أثر تطبيق قواعد حوكمة الشركات في أداء المصيارف الإسلامية:

حالة دول منطقة الخليج* مانهاء

شوقي عاشور بورقبة و عبدالحليم عمار غربي

أستاذ مساعد - أستاذ مشارك بولك

كلية الاقتصاد والعلوم الإدارية ألعاية

جامعة الإمام محمد بن سعود الإسلامية - الرياض والعاضية

المستخلص. هدفت الدراسة إلى تحديد العلاقة بين متغيرات

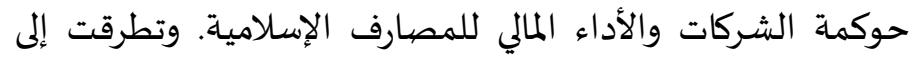

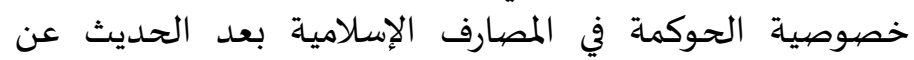

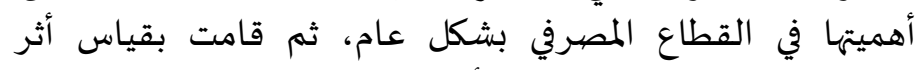

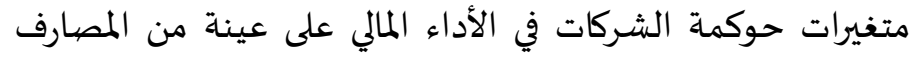

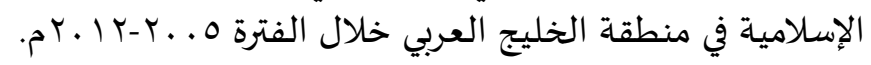

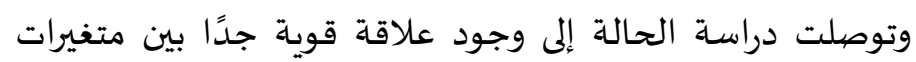

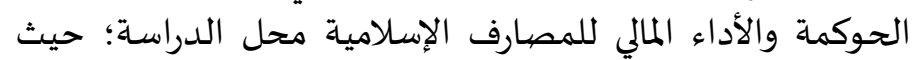

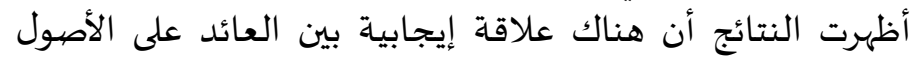

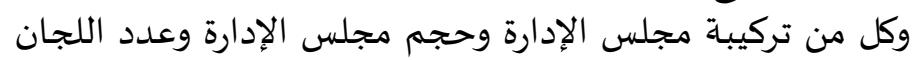

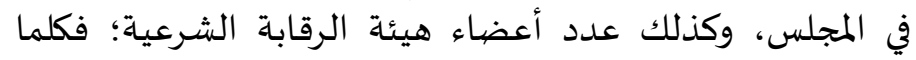

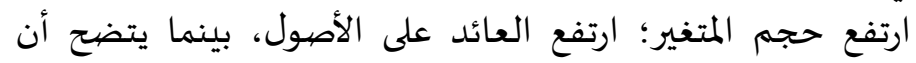
هناك علاقة سلبية بين العائد على الأصول ومتغير الأن تركز الملكية.

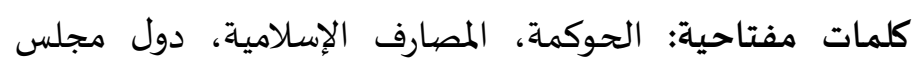

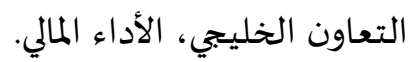

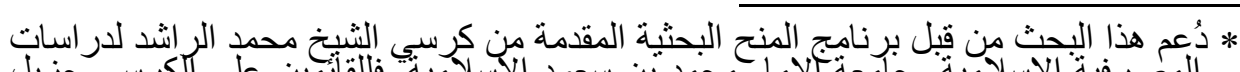

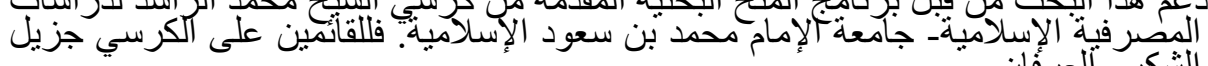




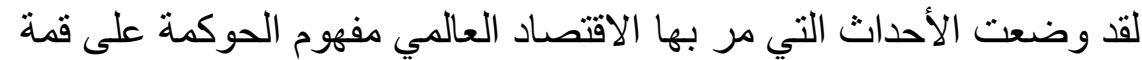

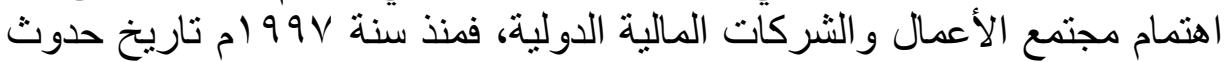

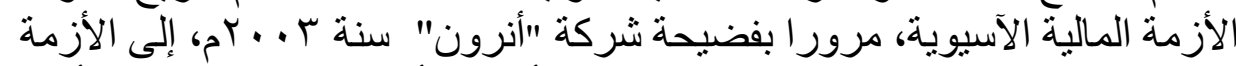

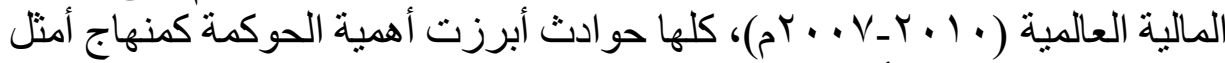
للمعالجة والوقاية من الأزمات. الماته

يتفق الكثير من الباحثين و المهتمين على أهمية حوكمة الثركات وما تمثلك

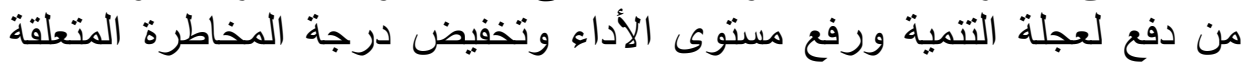
بالفساد الإداري و المالي على مستوى الثركات و والدول على على حد سواء.

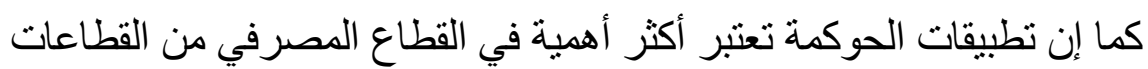

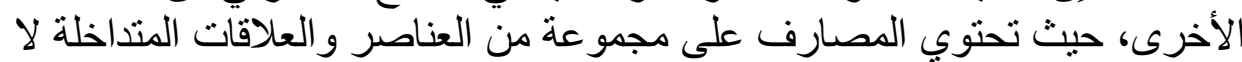

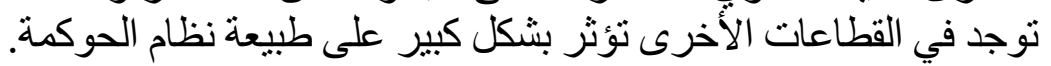

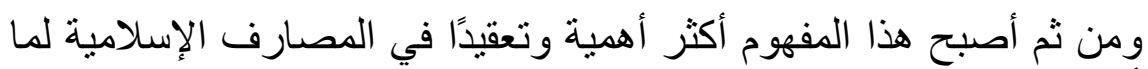

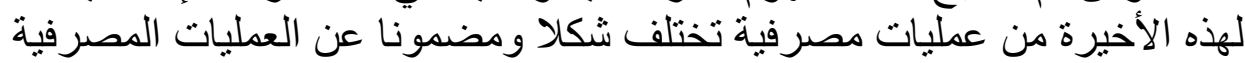

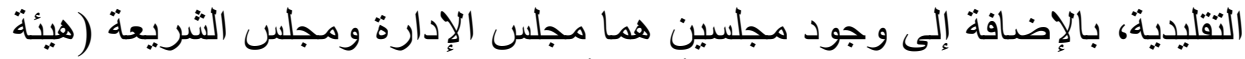

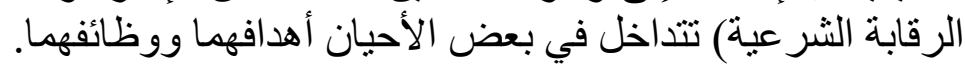

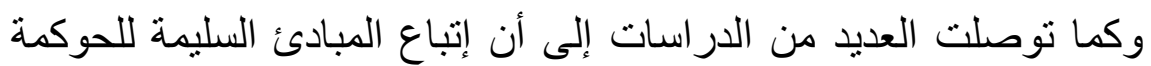

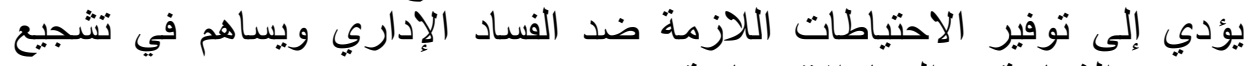
وترسيخ الثفافية في الحياة الاقتصادية.

من خلال ما سبق؛ تتضح إثكالية هذا البحث التي يمكن بلورتها في

إشكالية البحث

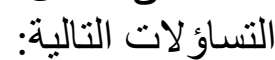

ـ ما طبيعة العلاقة بين متغير ات حوكمة الثركات والية الأداء المالي للمصارف الإسلامية؟

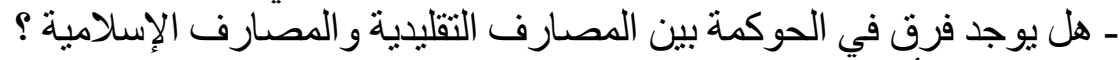

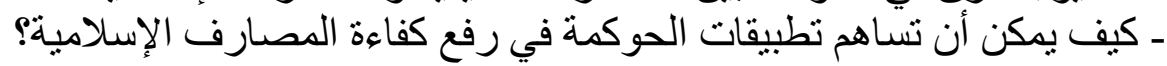

وللإجابة البحث هذه التساؤ لات قمنا بصياغة مجمو عة من الفرضيات هي:

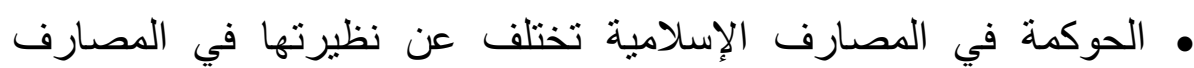
التقليدية، نظر اللاختلاف في المبادئ التي يقوم عليها نشاط كل شركة. • التطبيق الجيد لمبادئ الحوكمة يؤدي إلى تحسين كفاءة المصارفئ الإسلامية. 
أثر تطبيق قو اعد حوكمـة الثركات في أداء المصـارف الإسلاميـة: دراسة حالة دول منطقة الخليج

1

• توجد علاقة ذات دلالة إحصائية بين متغيرات حوكمة الشركات والأداء

المالي للمصارف الإسلامية.

• هنالك علاقة إيجابية بين كل من تركيبة مجلس الإدارة ولجان المجلس، الإسلة

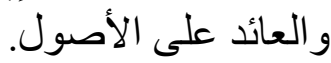

• هناك علاقة سلبية بين تركز الملكية، و العائد على الأصول.

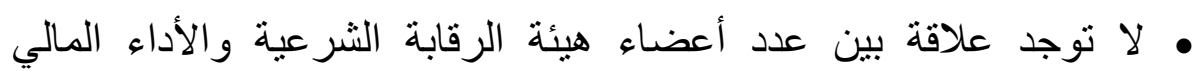

للمصارف الإسلامية.

خطة البحث

ولمعالجة هذا الموضوع قمنا بتقيم البحث إلى العناصر التالية:

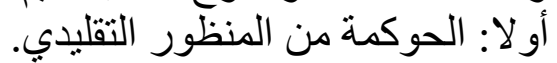

ثانيا: الحوكمة في القطاع الحن المنظور المصرفي.

ثالثا: الحوكمة من المنظة في المنظور الإسلامي.

رابعا: الحوكمة في المصنار فن المنظف الإسلامية.

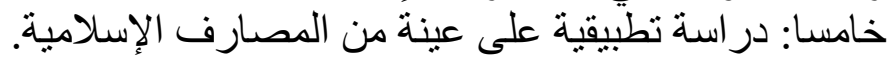

الارراسات السابقة

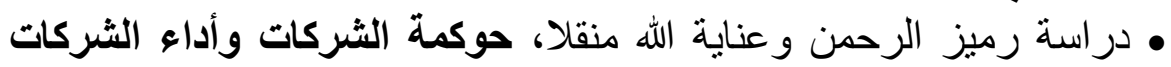

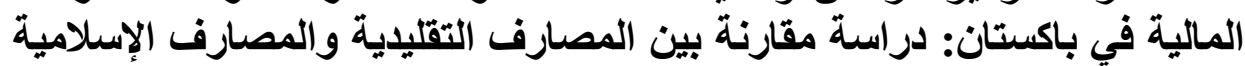

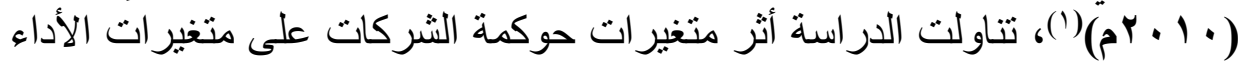

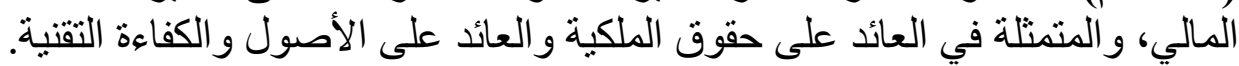

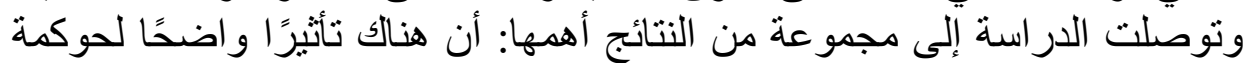

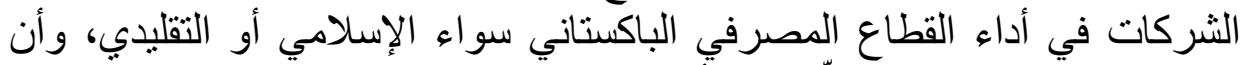

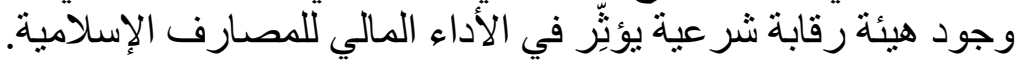

• در اسة حمادي متوسي ورحاب غراسة، هل تختلف حوكمة الشركات في

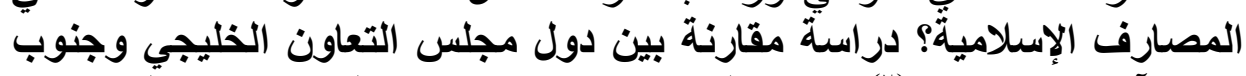

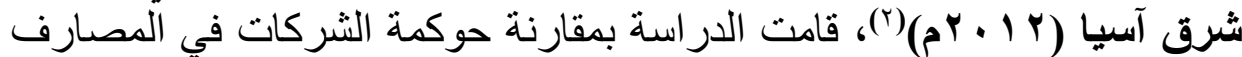

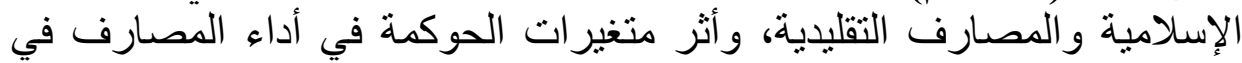

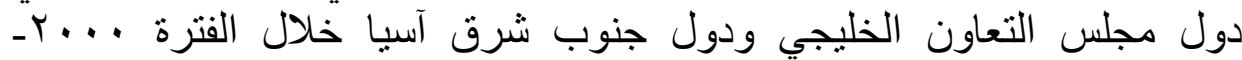

(1) Ramiz, U.R. and Mangla, I. (2010) "Corporate Governance and Performance of Financial Institutions in Pakistan: A Comparison between Conventional and Islamic Banks in Pakistan", the Pakistan Development Review, Pakistan.

(2) Matoussi, H. and Grassa, R. (2012) "Is Corporate Governance Different for Islamic Banks? A Comparative Analysis between the GCC Context and the SEA Context", Working Paper No.734, Economic Research Forum, Egypt. 


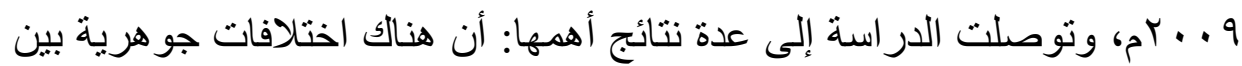

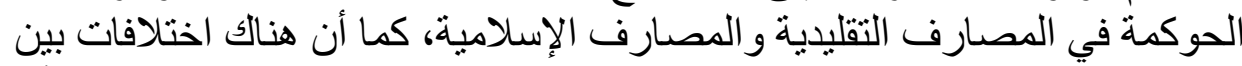

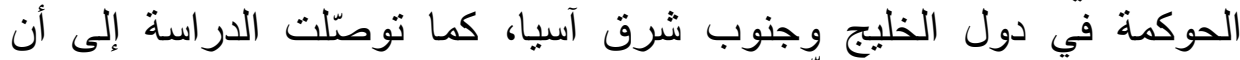

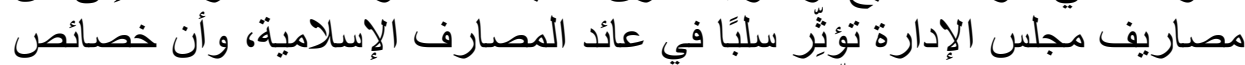

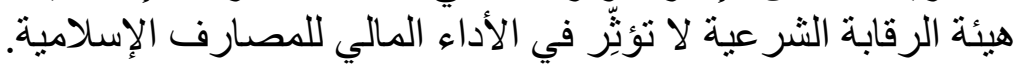

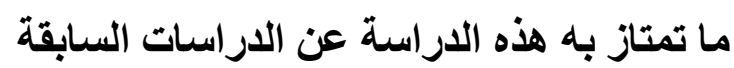
توجد الكثير من الدراسات التي تطرقت إلى قضية الدئل الحوكمة في الدصارف

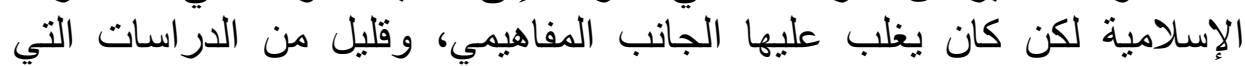

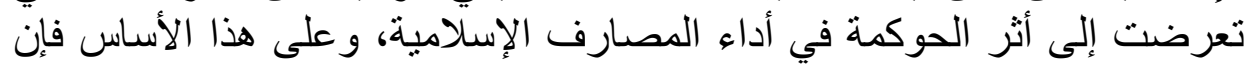

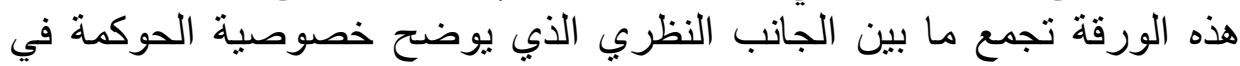

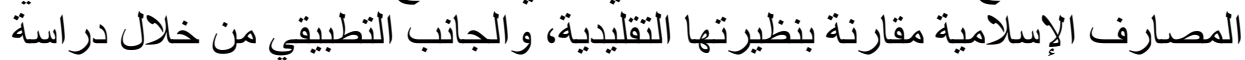

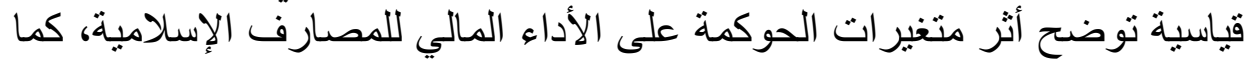

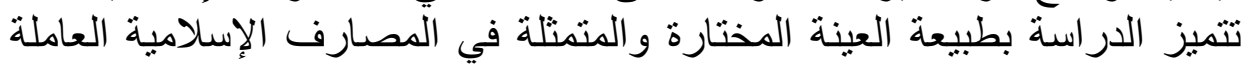

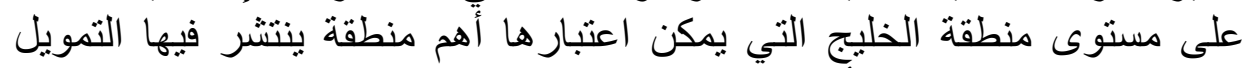

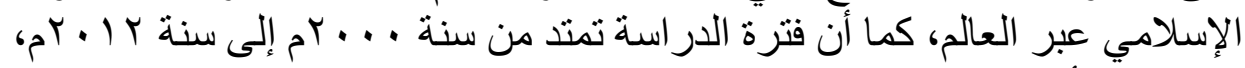
فهي تعتبر أحدث من الدراسات السابقة.

$$
\text { أولا: الحوكمة من المنظور التقليدي }
$$

يعتبر مصطلح الحوكمة مصطلحًا حديث الاستعمال في اللغة العربية بدأ

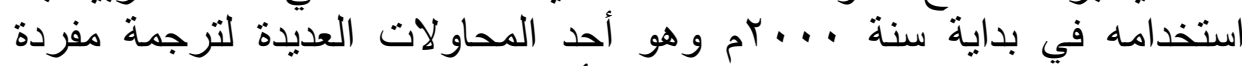
(Governance) اليونانية (Kubernan) في القرن الثالث عشر والذي كان بعني قيادة الباخرة الحربية

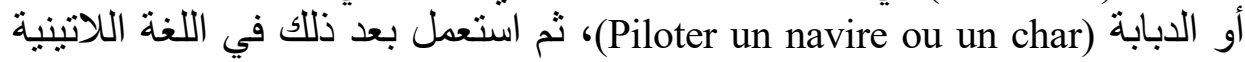
بكلمة (Gubernare) في بداية القرن الرابع عثر بنفس المعنى، ثم ظهر في سنة فئة فئن

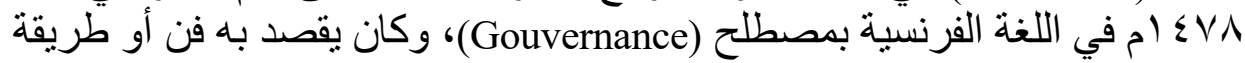

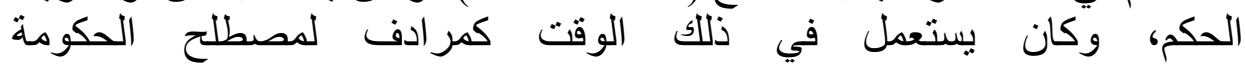

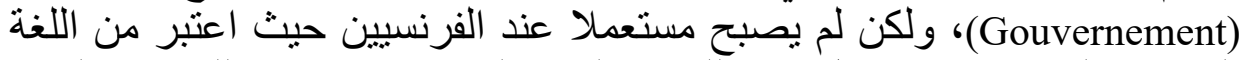

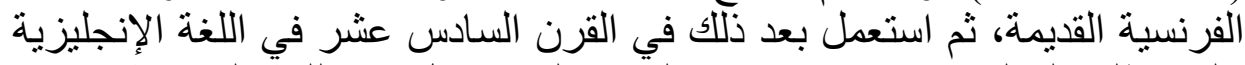

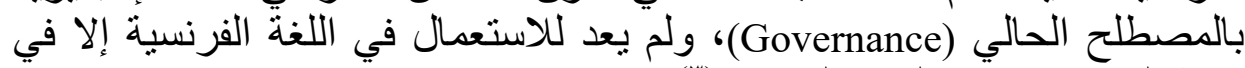
بداية التسعينيات من القرن العشرين(").

(3) Encyclopédie de wikipedia sur le site:

http://fr.wikipedia.org/w/index.php?oldid=45800587. 


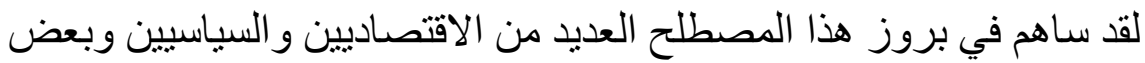

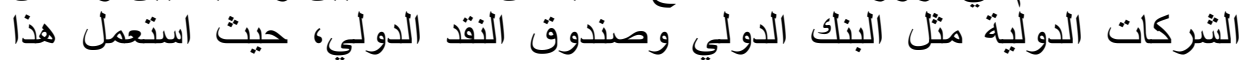

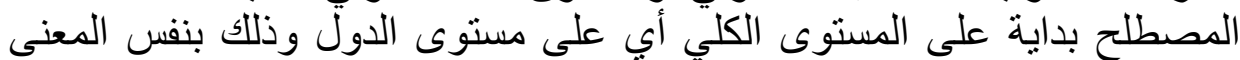
القديم، أي فن وطريقة الحكم مع إضأفة نقطنتين أساسيتين هما:

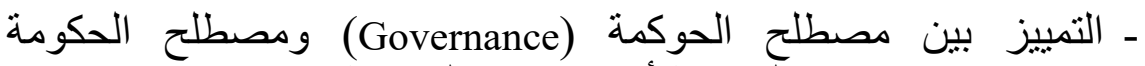
حيث تعتبر الحكومة أحد عناصر الحوكمة. (Governement) - تطوير نظام إدارة الأعمال العمومية يرتكز على مشاركة المجتمع المدني

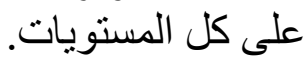

وبالتالي يمكن القول أن مصطلح الحوكمة استعمل أولا على المستوى الكلي

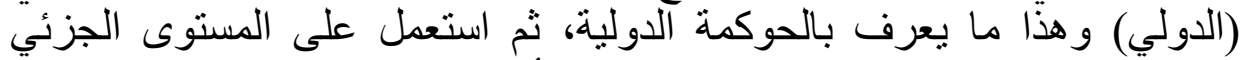
(الثركات) و هذا ما يعرف بحوكمة الثركات، أو الثركات.

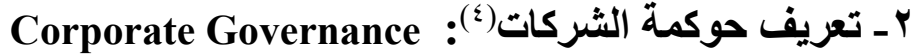

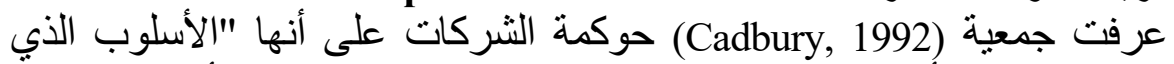
يحقق التوازن بين الأهداف الاقتصادية والاجتماعية من جهة، وبين وبين الأهداف الفرات الفردية و المشتركة من جهة أخرى، وأن إطار حوكمة الثركات يشجع على الأى الاستخدام الفعال

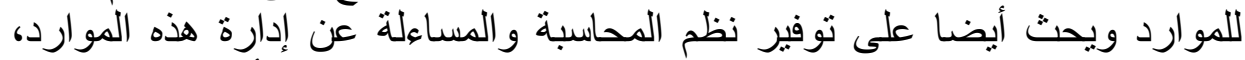

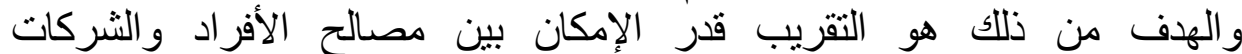

أمًا منظمة التعاون الاقتصادي و التتمية (OCED) فعرّفت الحوكمة على أنها

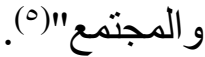

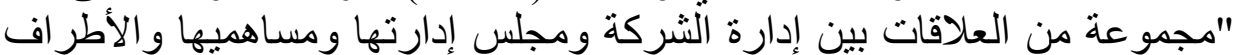

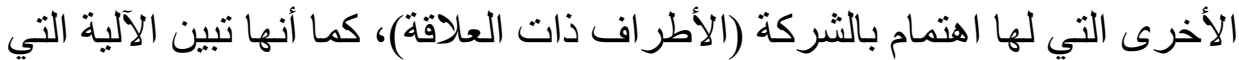

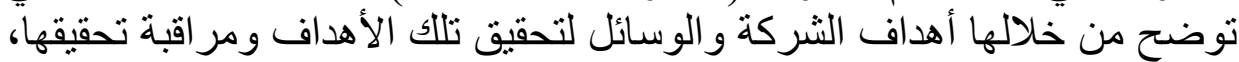
وبالتالي فإن الحوكمة الجيدة هي التي توفر لكل من المجلس والإدارة التهائ التنفيذية

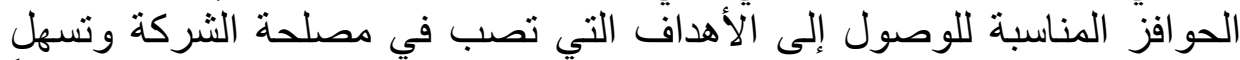
عملية إيجاد مر اقبة فعالة، وبالتالي تساعد الثركة على أستغلال مواردها استغلالاً

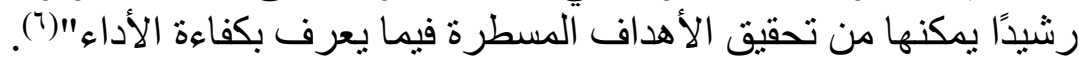
وتعرف أيضا بأنها الهيكل الذي تسعى من خلاله الثركة إلى تحقيق أهدافها

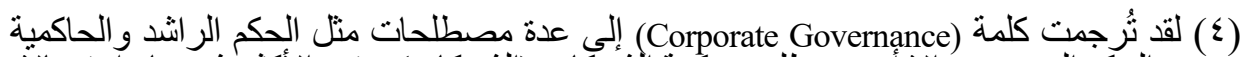

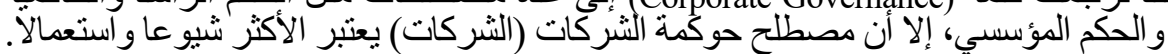

(5) Cadbury Committee (1992) Report of the Committee on the Financial Aspects of Corporate Governance, London, Gee and Co Ltd.

(6) Organization for Economic Co-operation and Development. (2000) Principles of Corporate Governance, OECD Publications Service. 
و الوسائل والطرق المتبعة عن طريق مجلس الإدارة الذي يلعب الدور المهان المهم في

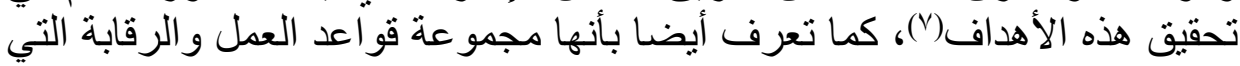

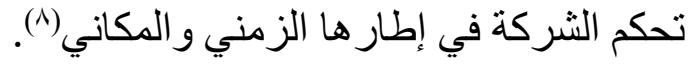

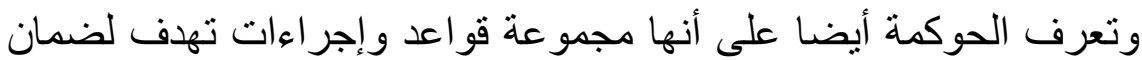

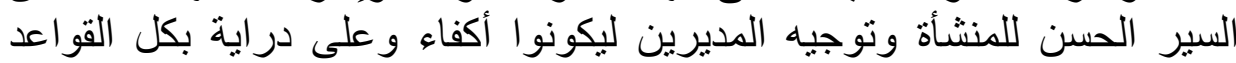
القانونية و الوظيفية(9)

يقول (Charkham) أن المشكل الجوهري للحوكمة هو إيجاد نوازن بين

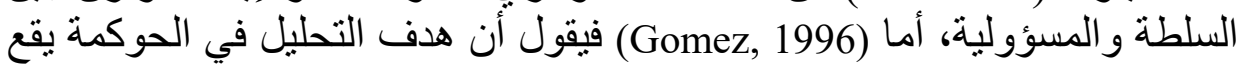

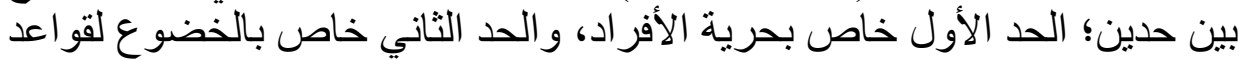

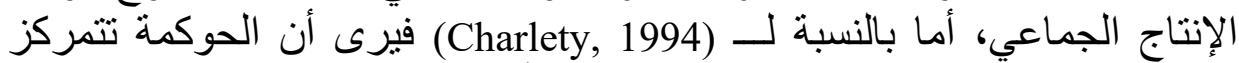

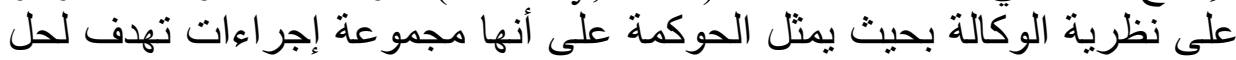

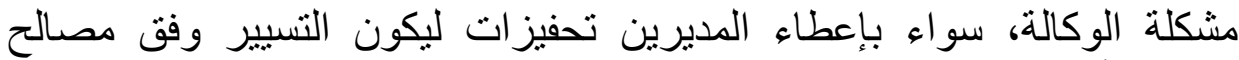

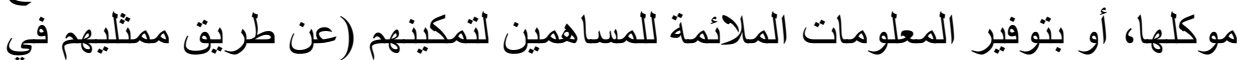

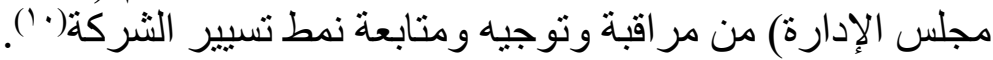

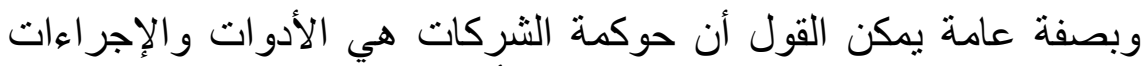

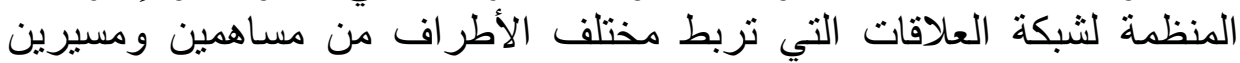

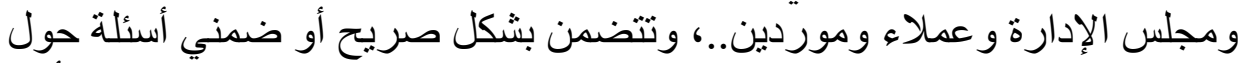
السلطة والرقابة والمسؤولية، في إطار تحديد استراتيجية التوجه العام لأداء

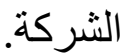

\section{rـ أسباب تزايد الاهتمام بمفهوم حوكمة الشركات في الآونة الأخيرة}

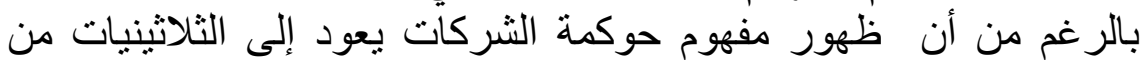

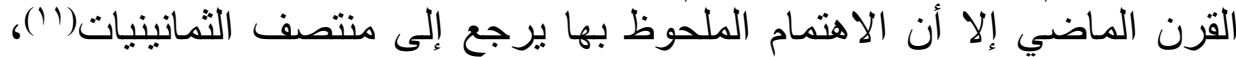

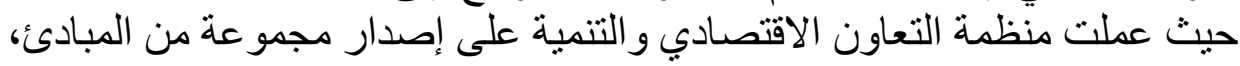

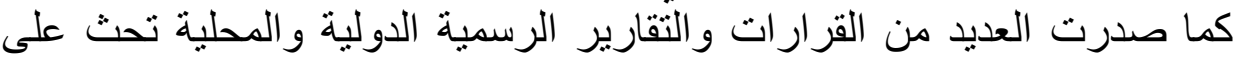

(7) Hirogoyen, G. and Caby, J. (2001) La création de valeur de l'entreprise, Economica, paris, p. 51

(8) Bessire, D. and Meunier, J. (2001) Conception du gouvernement des entreprises et modèles d'entreprise : une lecture épistémologique, Finance d'entreprise, CREFIB, Economica, Paris, p. 186.

(9) Plusieurs auteurs (1998) L'art de la finance, Glossaire Financial Times Limited, Village Mondial, Paris, p. 348.

(10) Bessire, D. and Meunier, J., op. cit, p. 187.

(11) Thierry, W.G. and el al. (2003) Développement durable et gouvernement d'entreprise: un dialogue prometteur, édition d'organisation, Paris, p. 102. 


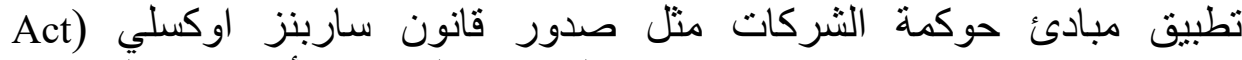
(Sarbanes-Oxley

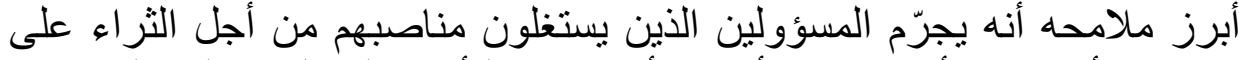

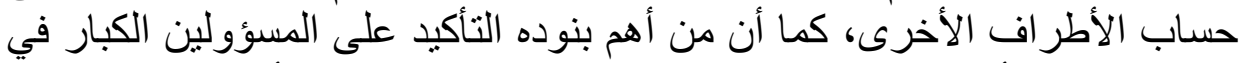

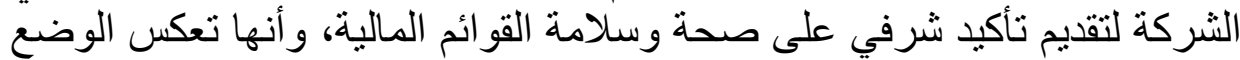

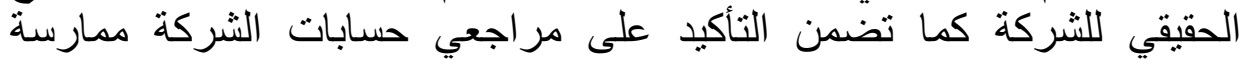

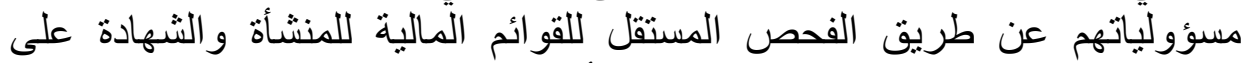

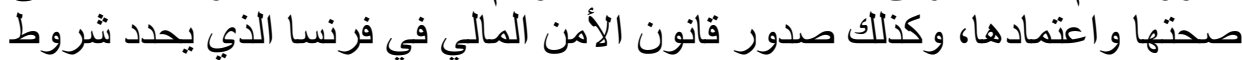

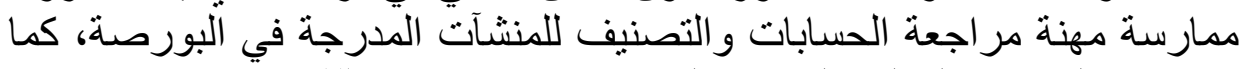

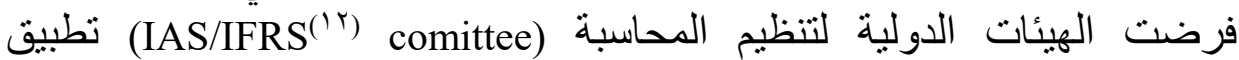

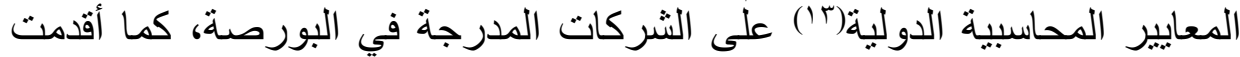

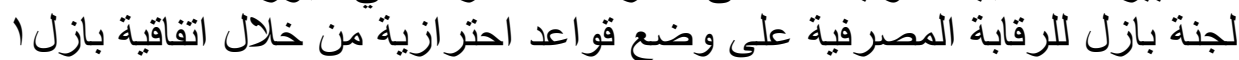

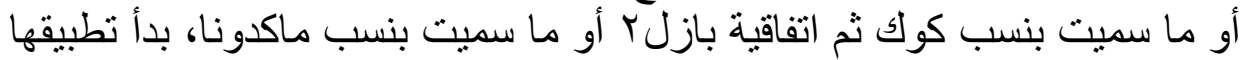

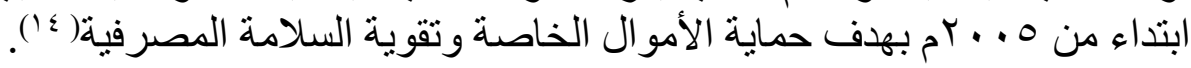

ويمكن تلخيص أسباب تز ايد الاهتمام بحوكمة الثركات في النقاط التالية:

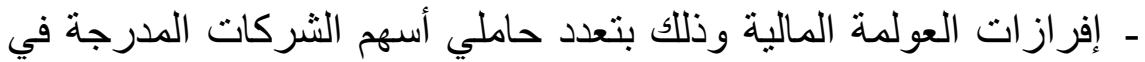

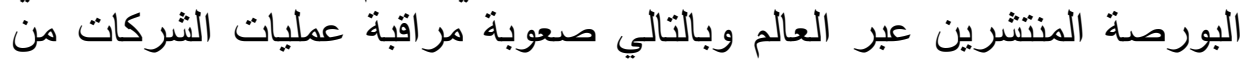

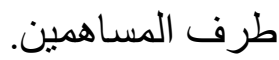

- سيطرة المديرين التنفيذيين على الثركة واستغلالها لمصالحهم الثخصية

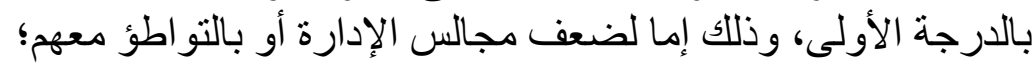

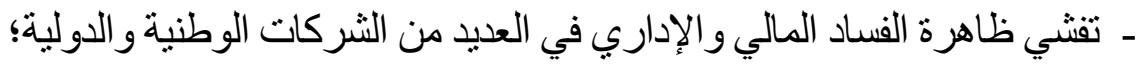

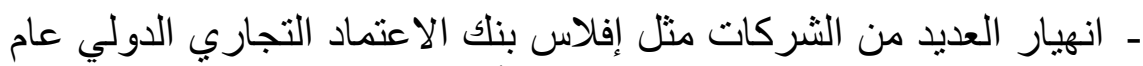

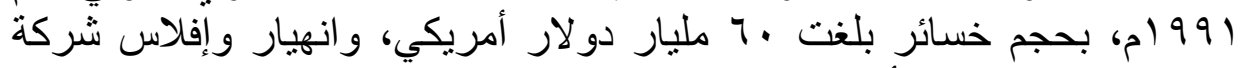

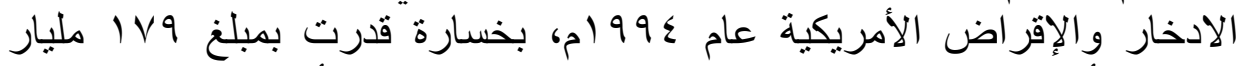

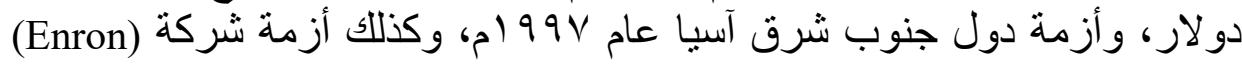

(12) - IAS: International Accounting Standard - IFRS: International Financial Reporting Standard

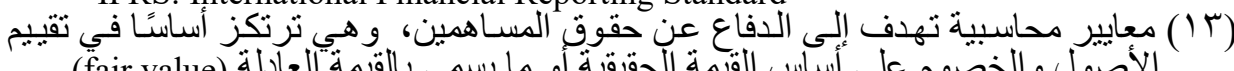

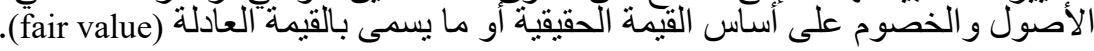

(14) Zied, C. and Pluchart, J.J. (2006) la gouvernance de la banque islamique, proposition de communication, p. 3 . 


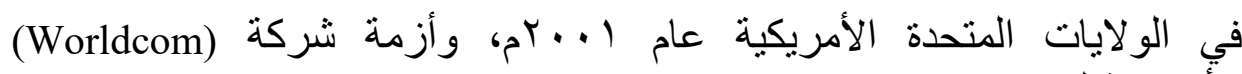

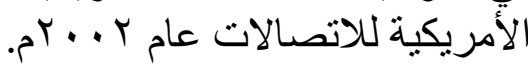
ع - مبادئ حوكمة الشركات

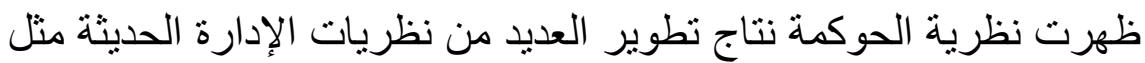

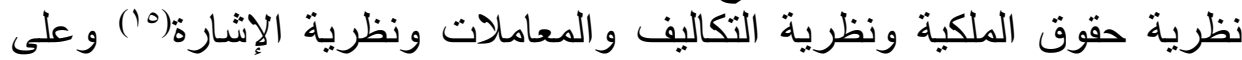

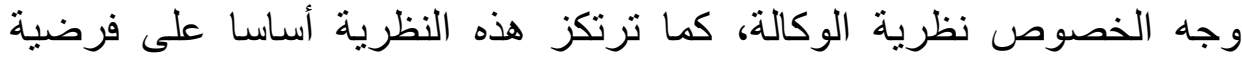

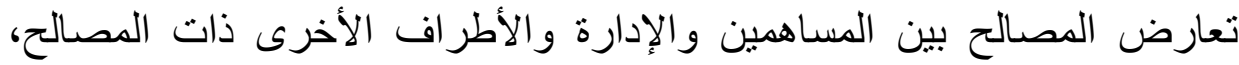

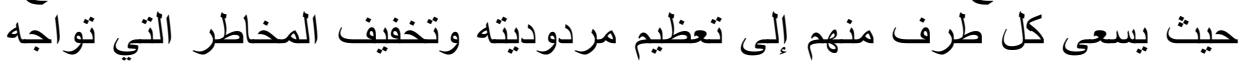

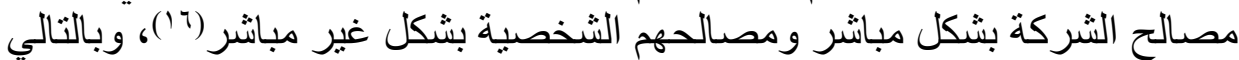

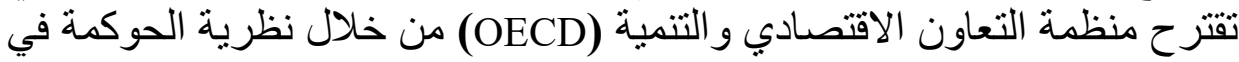

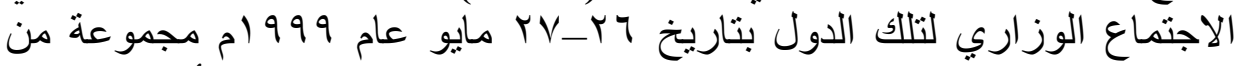

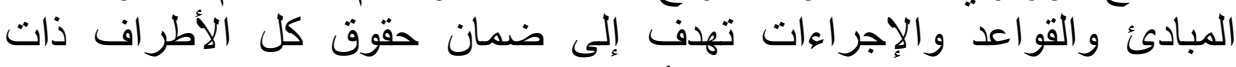
المصلحة ومن ثم الرفع من كفاءة أداء الثركة الثرات ، ويمكن تلخيصها في النقاط التالية(') (lv)

- توفير الحماية للمساهمين من خلال تأمين أساليب نقل الملكية و المشاركة الفعالة في التغييرات الأساسية بالثركة، والإفصاح عن عن الإجراءات المالية المالية بالثر كة.

ـ المعاملة المتساوية لكافة المساهمين حيث بضمن إطار حوكمة الثركات

تحقيق المساو اة في معاملة كافة المساهمين بمن فيهم الأقلية و المساهمين الإنة الأجانب.

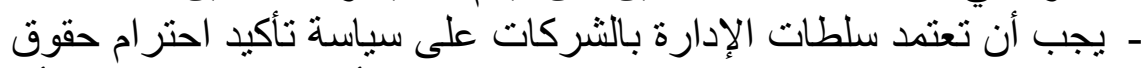

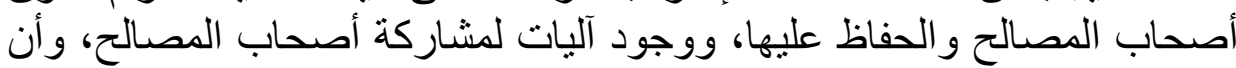
تكفل تلك الأولويات عنصر تحسين مستويات الأداء، وذلك من خلانل الإفصاح التهاح السليم عن القوائم المالية.

- يجب أن يضمن إطار حوكمة الثركات تحقيق الإفصاح و الثفافية في

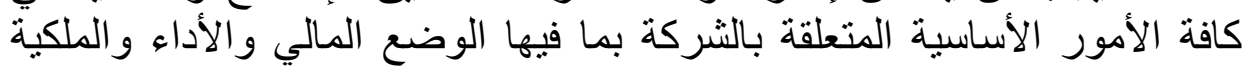

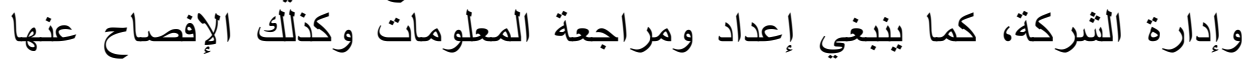

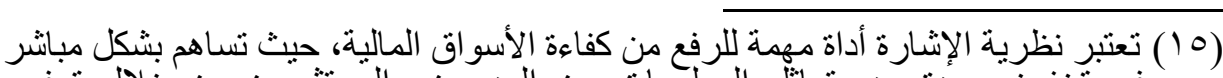

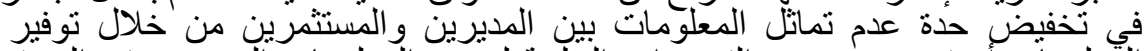

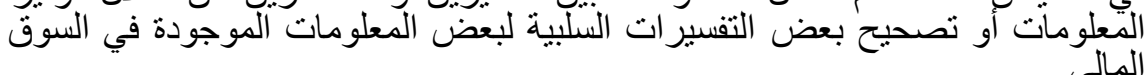

(16) Charreaux, G. (2002) à la recherche de nouvelles fondations pour la finance et la gouvernance d'entreprise, Finance Contrôle Stratégie, 5(3), p. 26.

(17) Bancel, F. (1997) la gouvernance des entreprises, Economica, Paris, p.35. 
بأسلوب يتفق و المعايير المحاسبية والمالية بما يؤدي إلي ضمان التوجيه و الرقابة

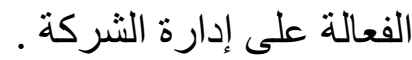

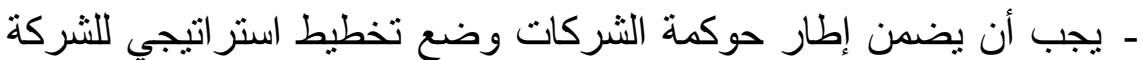

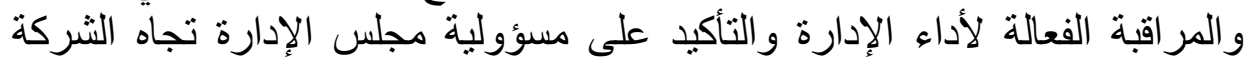
و المساهمين، بما يؤدي إلى إدراك الثركات الثرات للمصالح البيئية و الاجتماعية للمجتمعات.

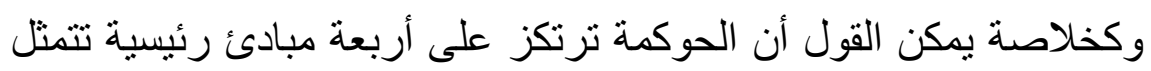
في العدالة، و المسؤولية، و المساءلة، وألة الثنفافية. هـ - أهية حوكمة الثركات

يتفق الكثير من الباحثين و المهتمين على أهمية حوكمة الثركات ومات وات تمثلكه من

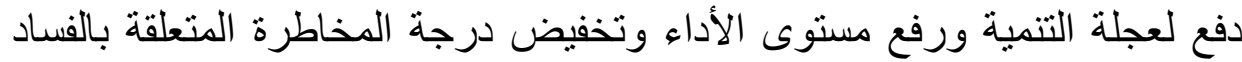

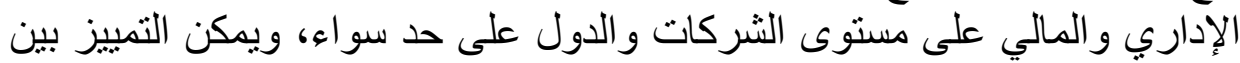

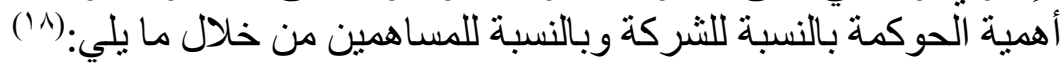

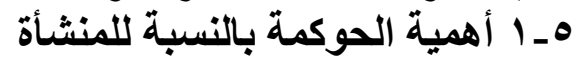

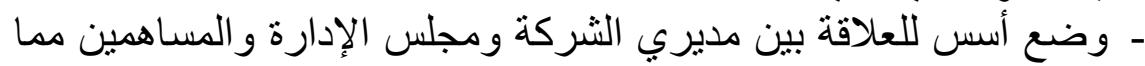

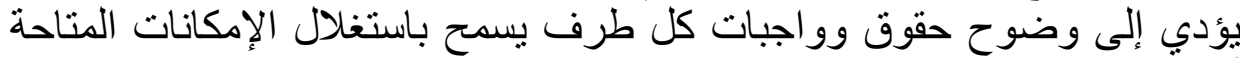
أحسن استغلال مما يرفع الكفاءة الاقتصادية للشركة.

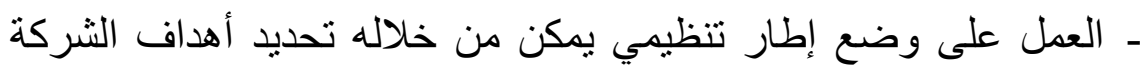

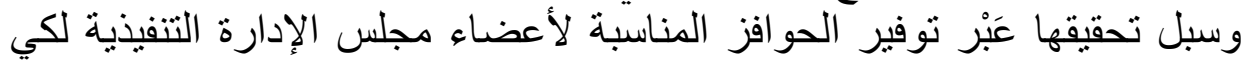
يعملو ا على تحقيق تلك الأهداف التي تر اعي مصلحة المساهمين.

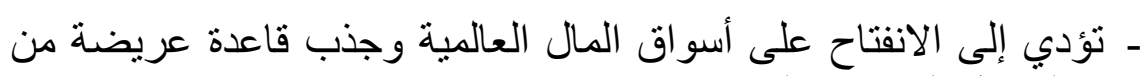
المستثرين لتمويل المشاريع التوسعية.

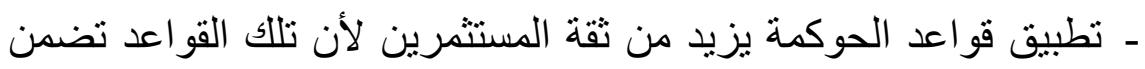
حماية حقوقهم. P_ P أهية الحوكمة بالنسبة للمساهمين

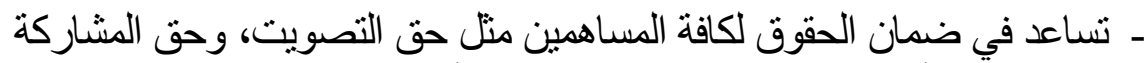
في القرارات الخاصة بأي تغيرات جوهرية قد تؤثر على أداء الثركة في المستقلى.

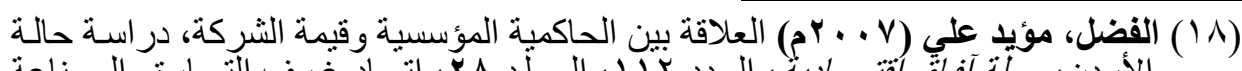

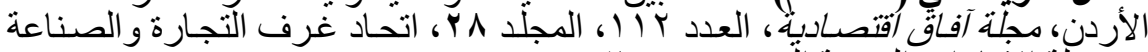

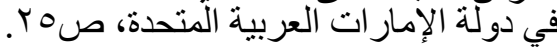




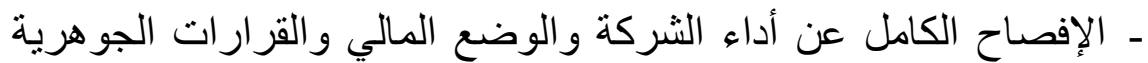

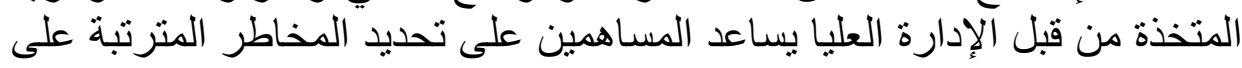
الاستثمار في هذه الثركات.

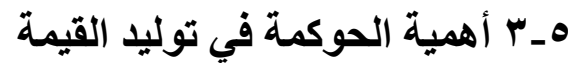

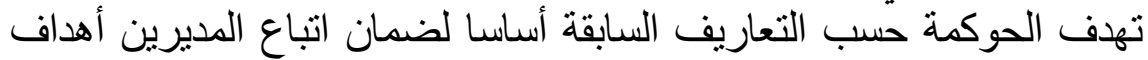

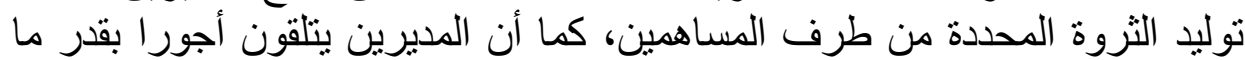

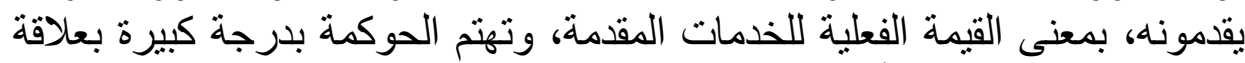

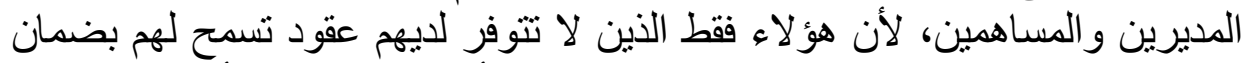

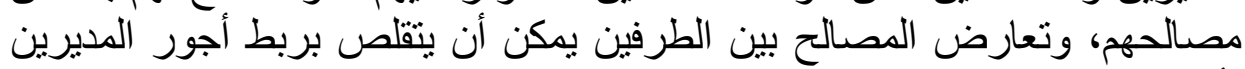

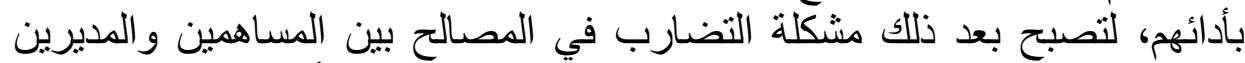

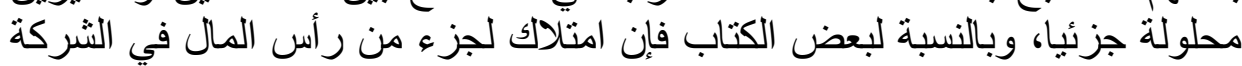

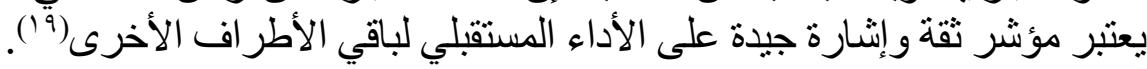

ولقد عبر (Leland \& Pyle, 1977) بوضوح عن المحتوى المعلوماتي لهذه

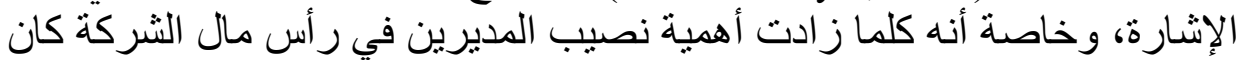

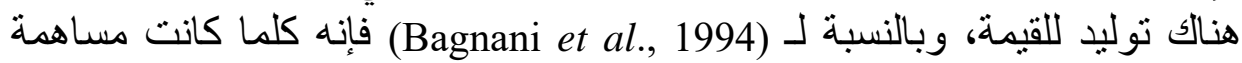

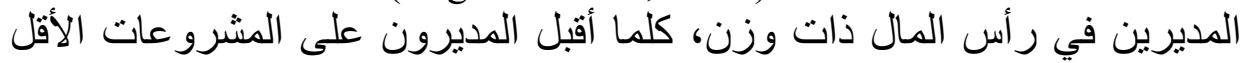

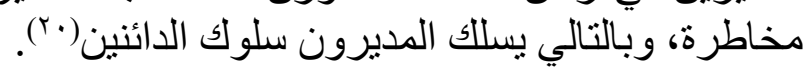

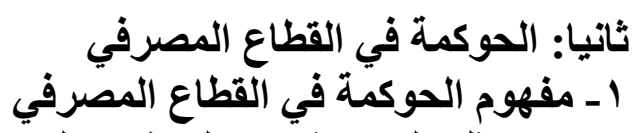

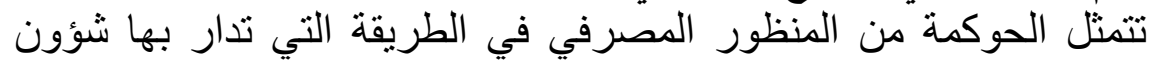

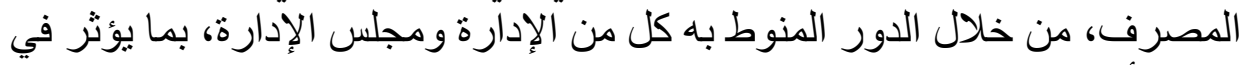

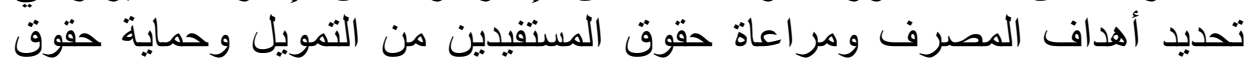
المودعين(r') المداف

\section{r ـ أهمية الحوكمة في القطاع المصرفي}

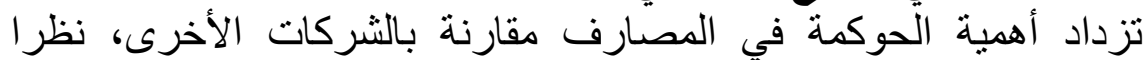

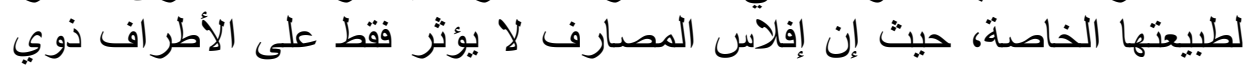

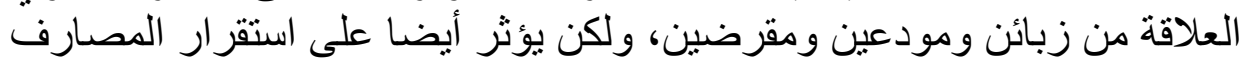

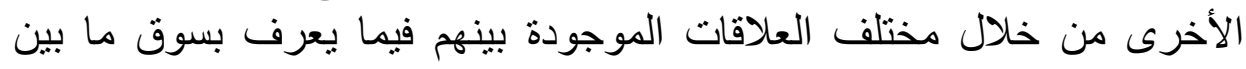

(19) Nguena O.J. et al. (2001) Introduction au management de la valeur, Dunod, Paris, pp: 54-55.

(20) Ibid, p. 131.

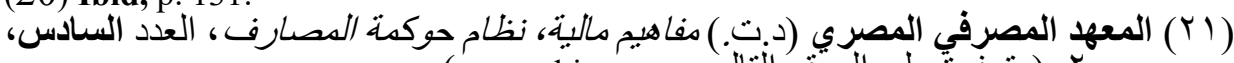

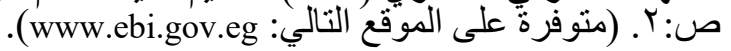




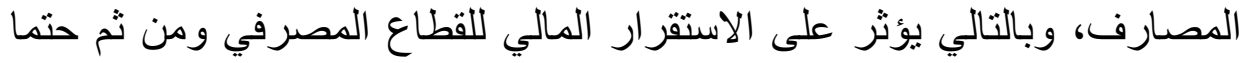

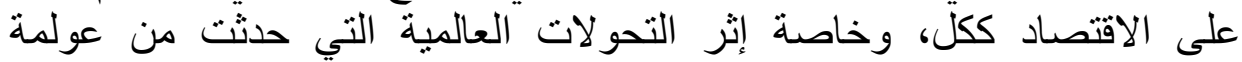

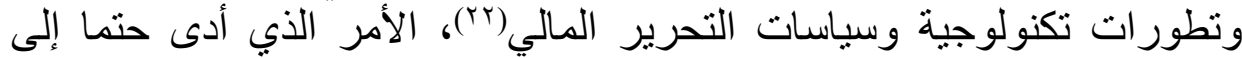

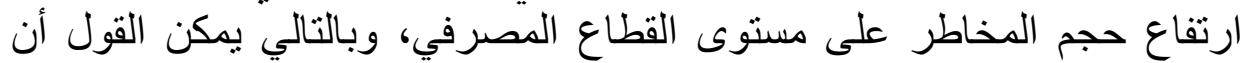

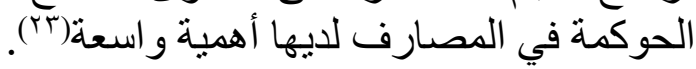

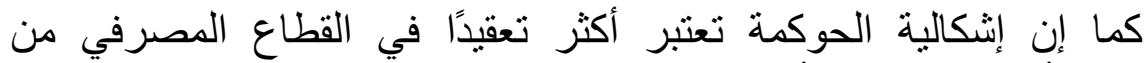

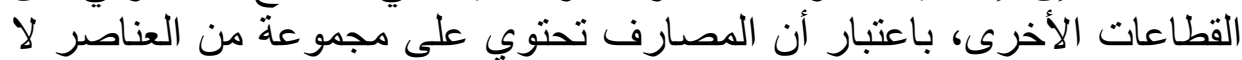

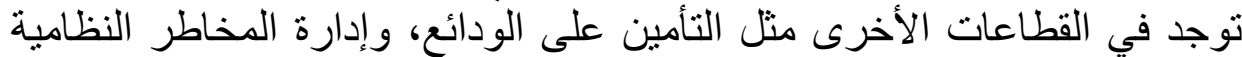

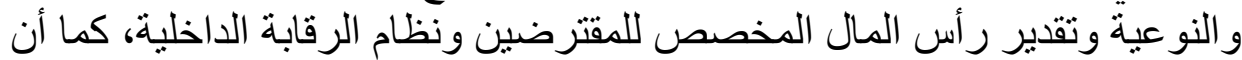

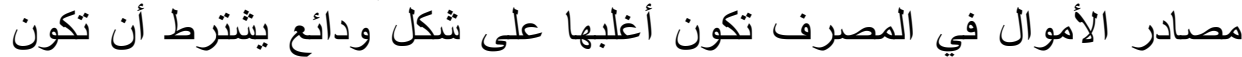

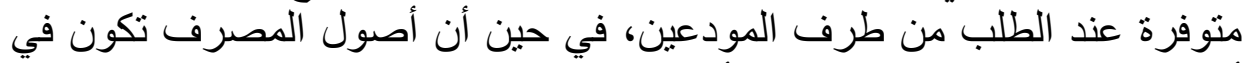
أغلبها قروض متوة عندة وطويلة الأجل.

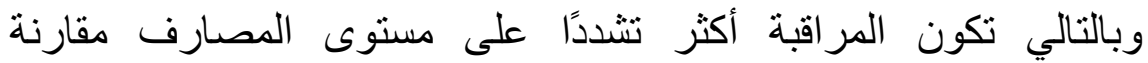

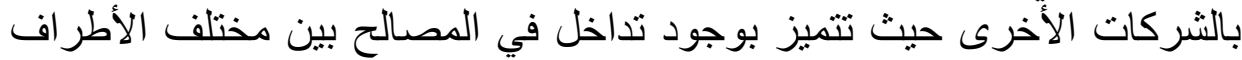

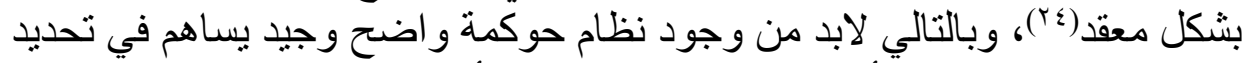

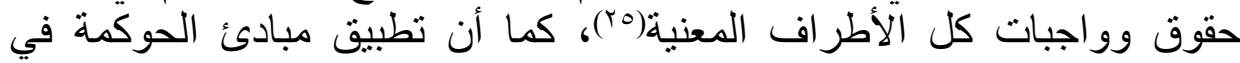

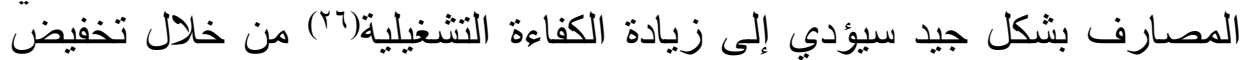

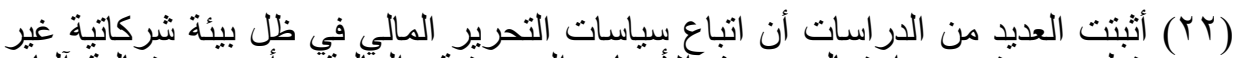

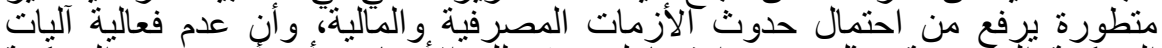

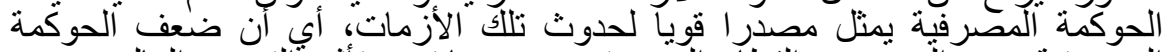

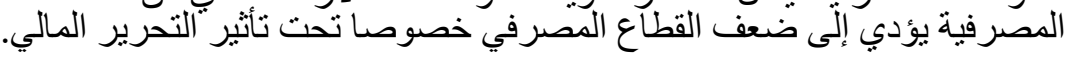

(23) Louizi, G. (2006) L'impact du conseil d'administration sur la performance des banques tunisiennes, XVème Conférence Internationale de Management Stratégique, Annecy / Genève 13-16 Juin, pp: 3-4.

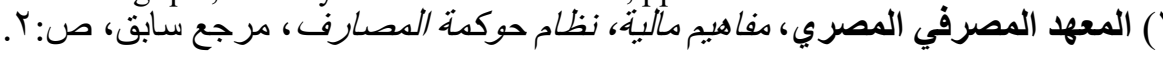

(25) Mehram, H. (2004) Corporate Governance in the Banking and Financial Services Industries, Journal of Financial Intermediation, vol. 13, p. 05.

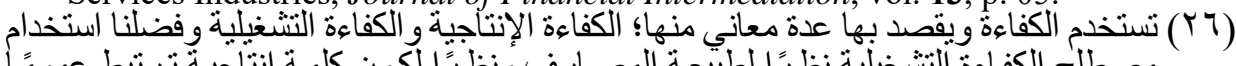

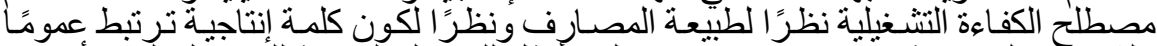

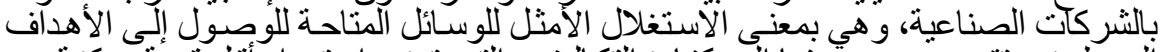

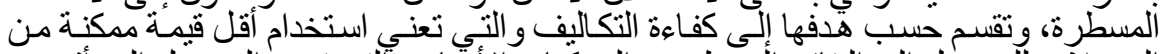

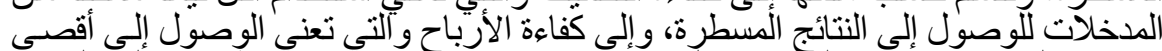

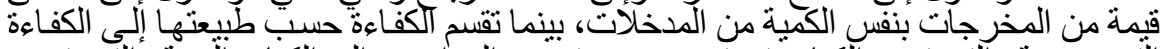

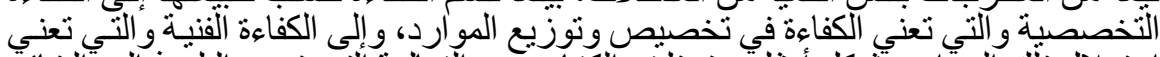

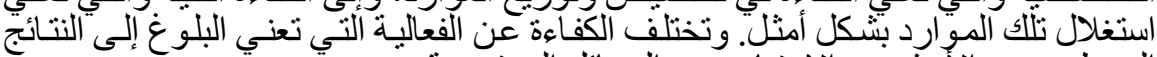
المسطرة دون الاخذّ بعين الاعتبار حجم الوسائل المستخدمة. 
تكاليف المدخلات وتعظيم أرباح المخرجات الأمر الذي يسمح بارتفاع قيمة الثركة

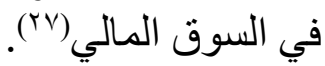

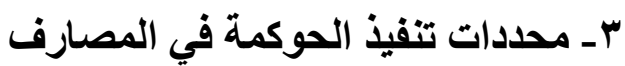

يتوقف التطبيق الجيد للحوكمة المصرفية على المئى جودة مجموعنين من المحددات هي)

ـ المحددات الداخلية: حيث تتمثل في القواعد والأسس التي تحدد طريقة

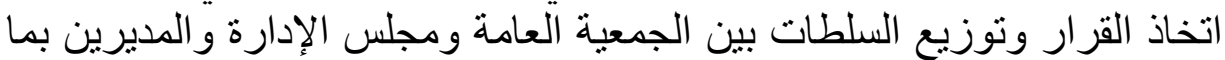
يؤدي إلى تخفيض التعارض الت بين مصالح هذه الأطر اف. ـ المحدات الخارجية: تتمثل في عناصر تتظيمية تتضمن المناخ العام

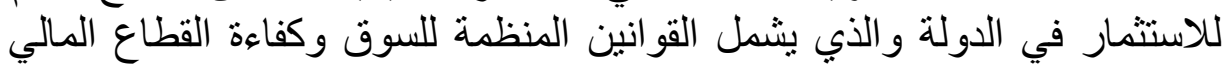

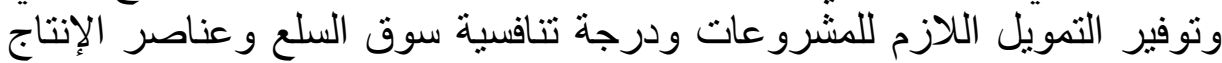

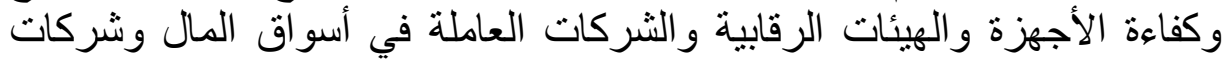

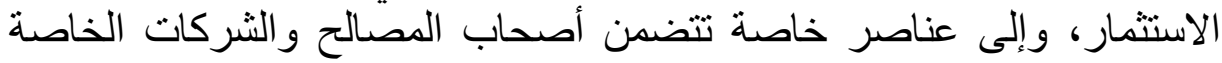
و المهنيين من المحاسبين و المر اجعين و القانو نيين و غير الفير هم.

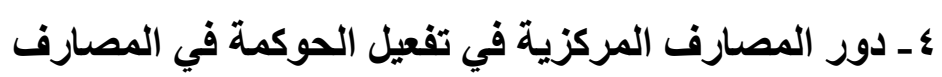

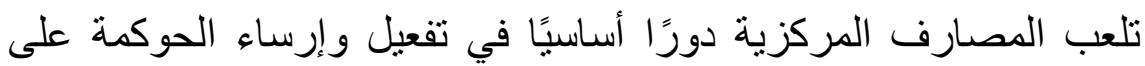

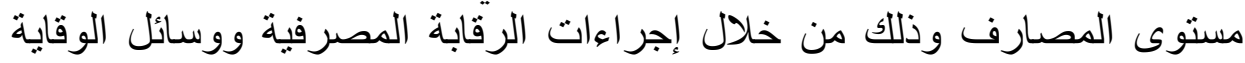

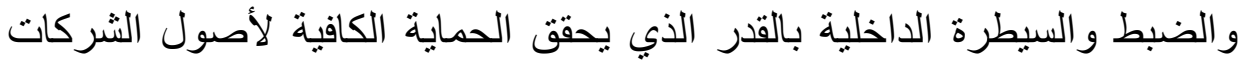

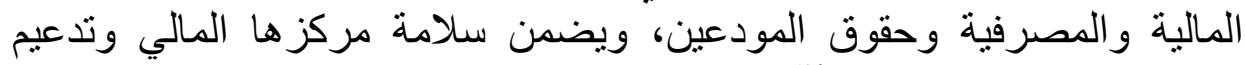

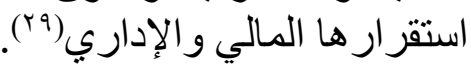
أثالثا: الحوكمة من المنظور الإسلامي

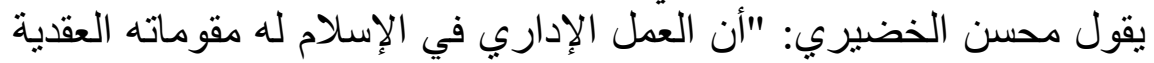

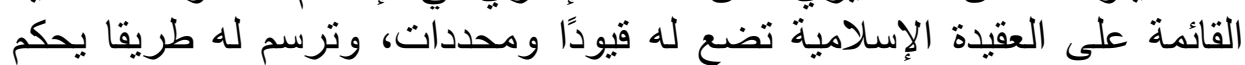

(27) Sebastian, M. (2007) International and Mena wide trends and developments in bank and corporate governance, the institute of banking - IFC: corporate governance for banks in Saudi Arabia forum, Riyadh, 22-23 may, p: 06.

(28) Fawzi, S. (2003) Assessment of corporate governance in Egypt. working paper $n^{\circ} 82$, the Egyptian Center of Economic Studies, Egypt, p: 04.

(29) Jean-Pierre, P. (2000) la stabilité financière nouvelle urgence pour les banques centrales, bulletin de la banque de France, No. 84, p. 07. 


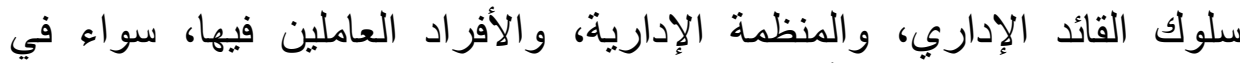

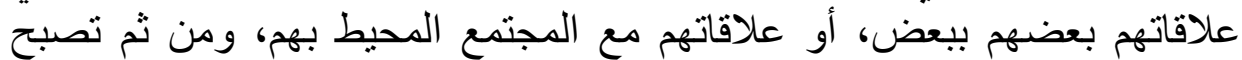

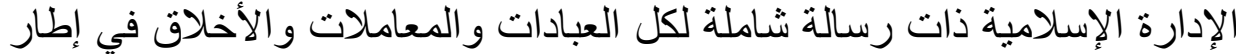

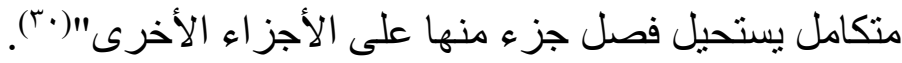

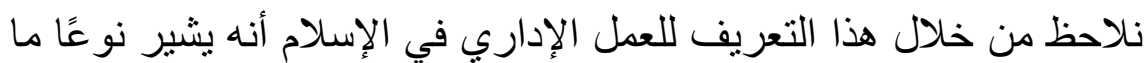

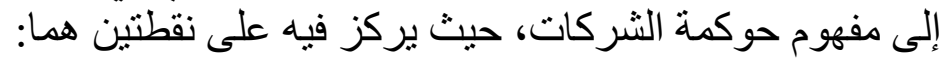

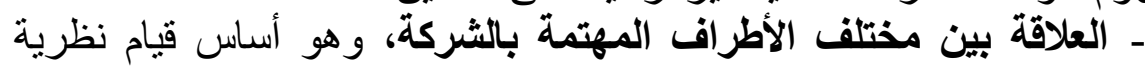
الحوكمة أي ضبط العلاقة بين كل الأطر اف بشكل بعالج مشكلة تعارض المشاف المصالح؛ ـ دور مبادئ الثريعة الإسلامية في تفعيل هذا العلاج، و المتمثلة أساسا في

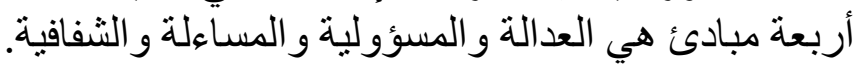
r - مبادئ حوكمة الشركات من منظور إسلامي:

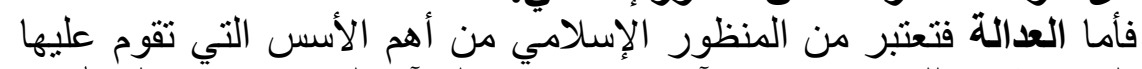

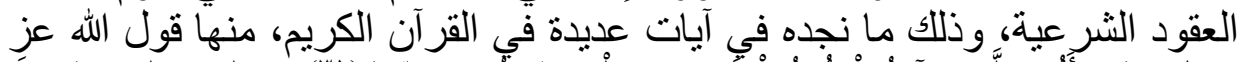

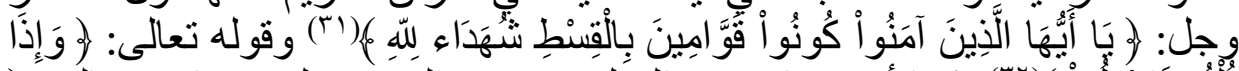

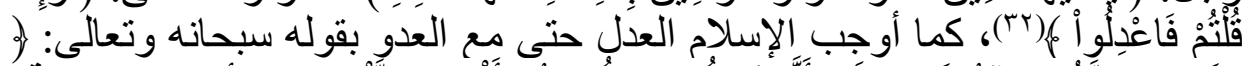

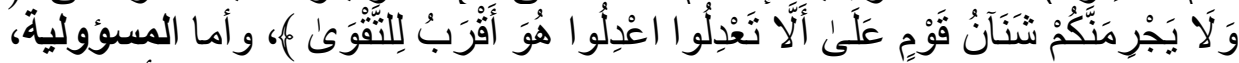

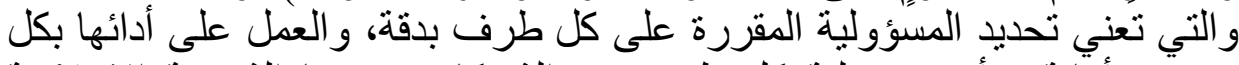

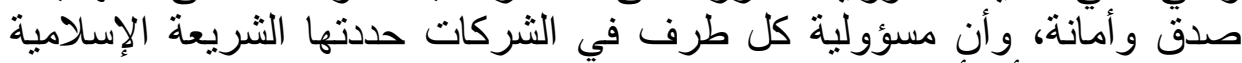

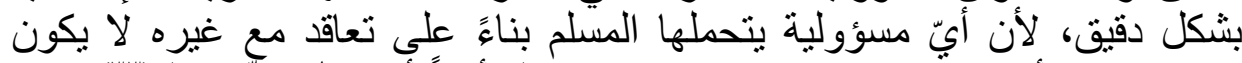

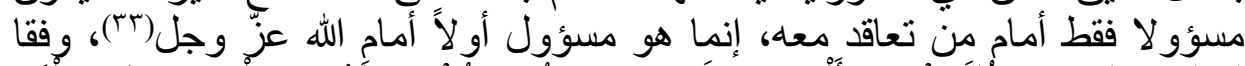

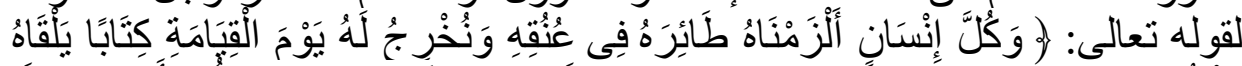

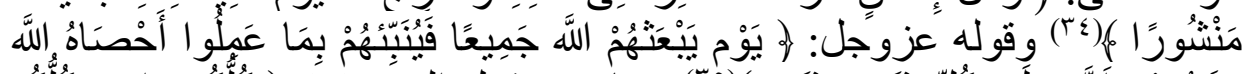

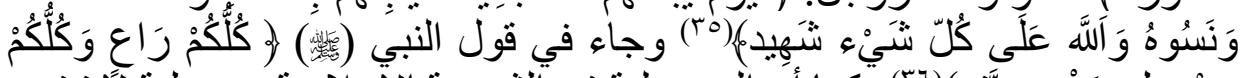

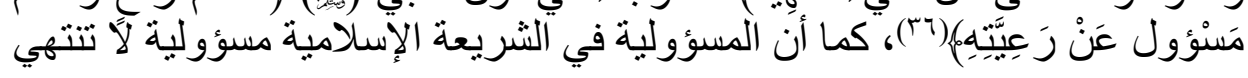

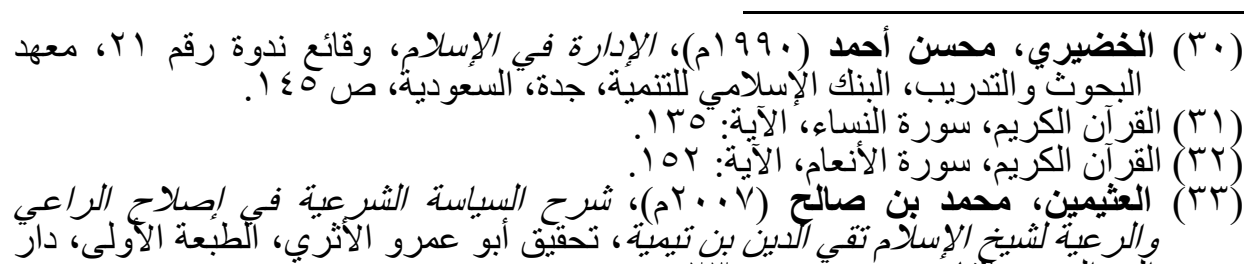

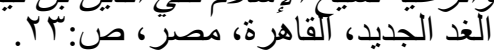

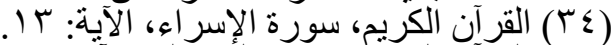

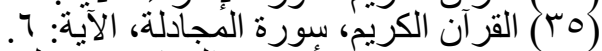

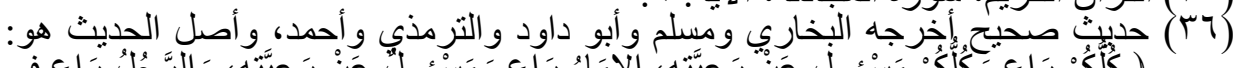

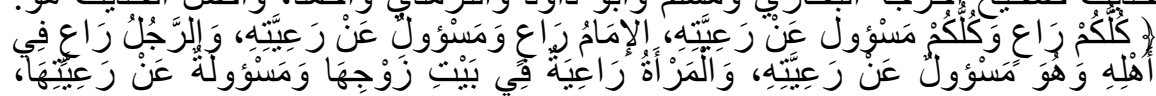


بقرار اتخذ في ضوء البيانات و المعلومات الصادقة، بل هي ممتدة إلى نتائج هذا

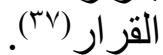

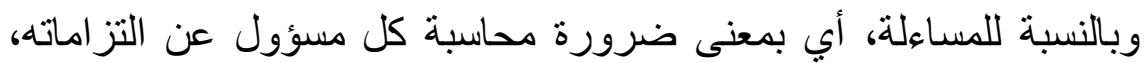

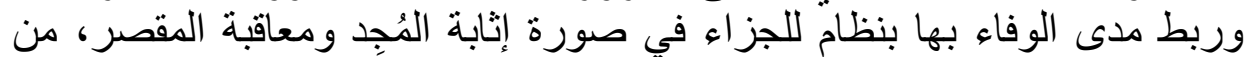

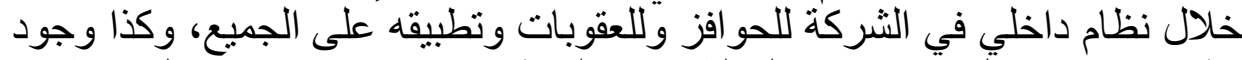

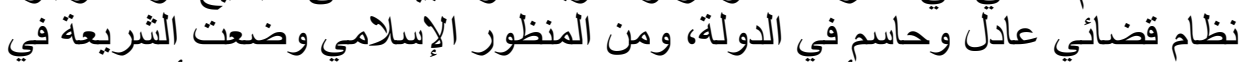

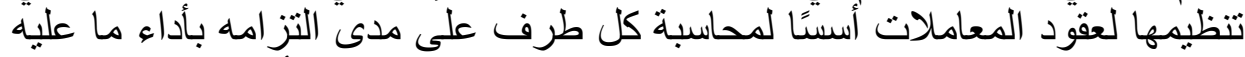

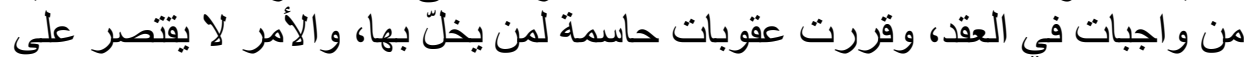

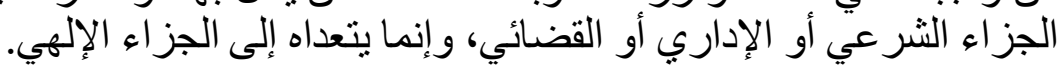

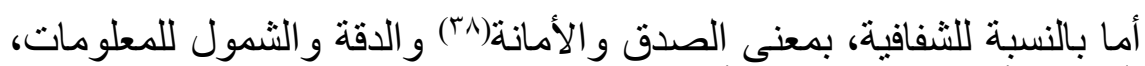

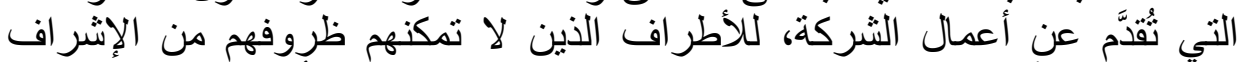

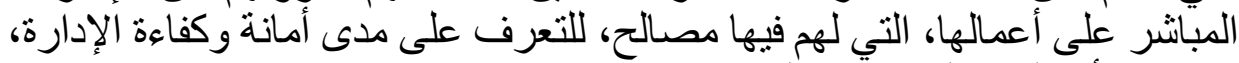
في إدارة أمو الهم و المحافظة على لعى حقوقهم.

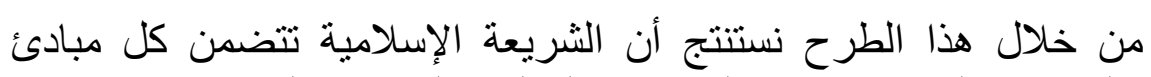

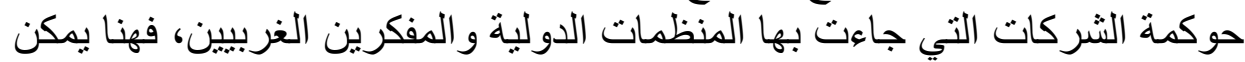
أن بطرح السؤال التالي: هل المصارف التئ الإسلامية بغنى عن تطبيق مبادئ حوكمة

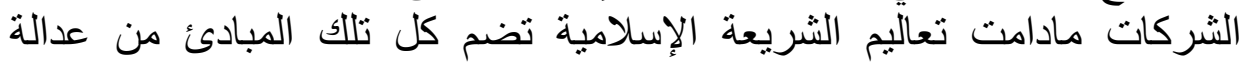

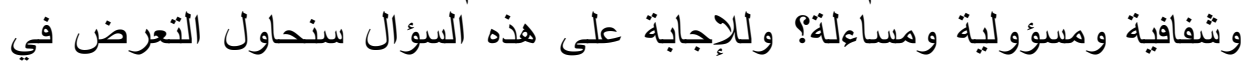
العنصر المو الي إلى الحوكمة في المصارفة وله الإسلامية.

رابعا: الحوكمة في المصارف الإسلامية البهارية

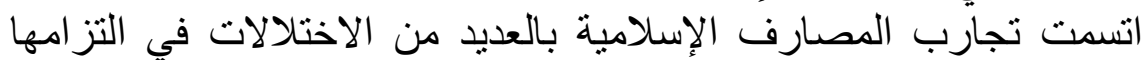

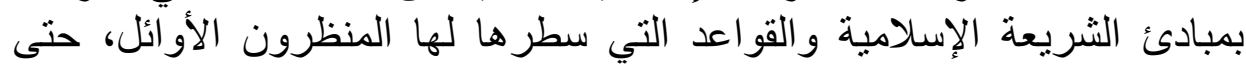

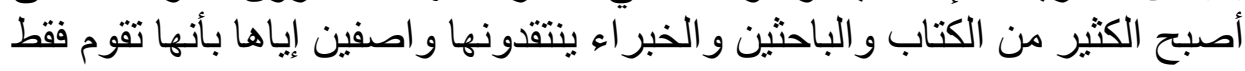

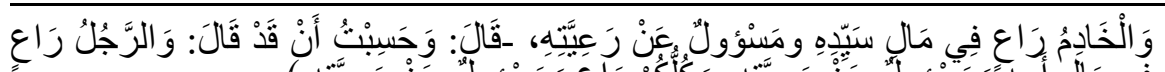

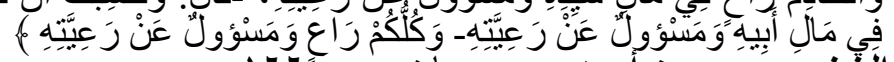

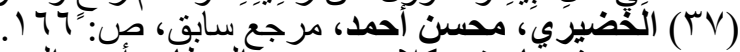

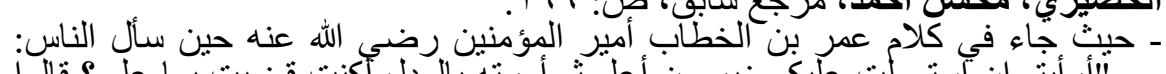

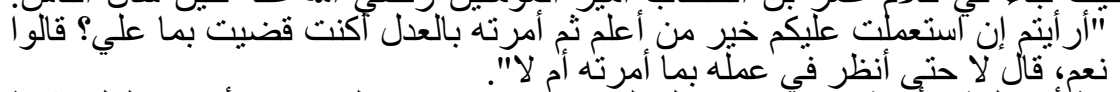

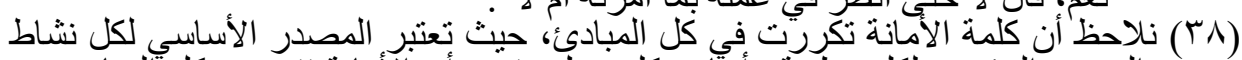

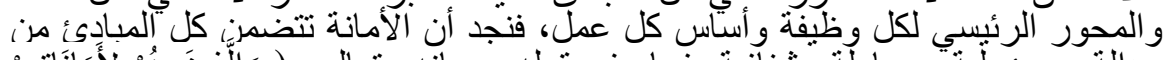

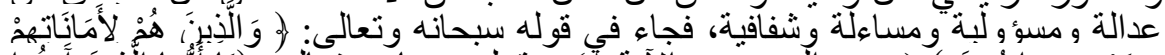

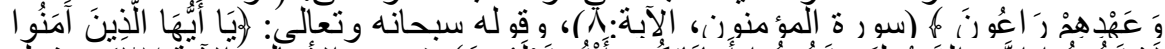

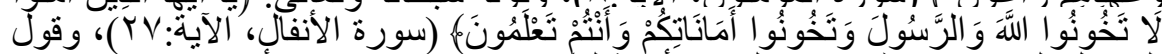

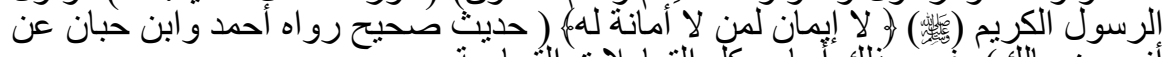

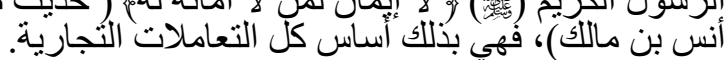


بمحاكاة عمليات المصارف التقليدية عبر عدد من الآليات والوسائل - الحيل

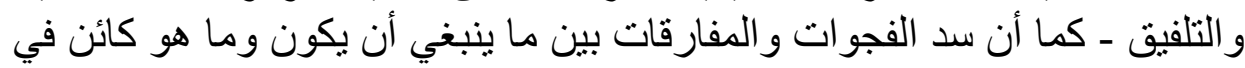

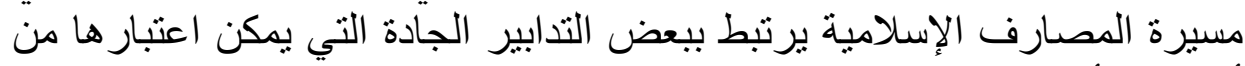

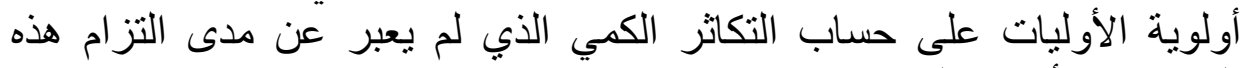
المصارف بأسسها النظرية.

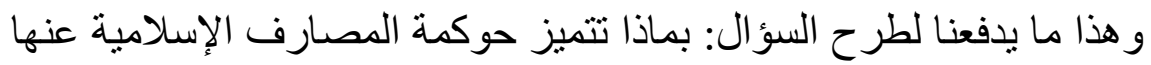

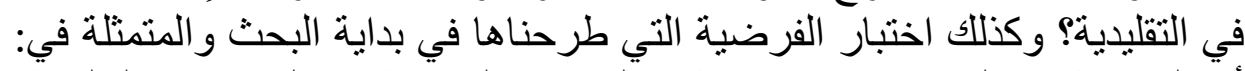

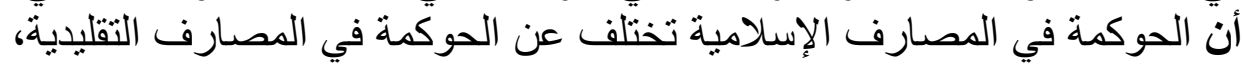
نظرًا لاختلاف المبادئ التي يقوم عليها كلا النئل النمطين.

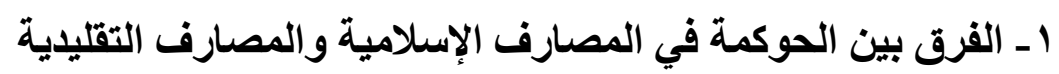

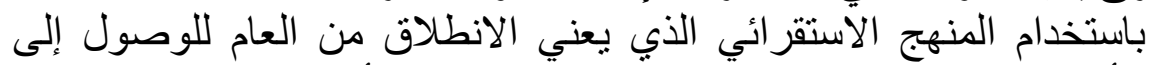

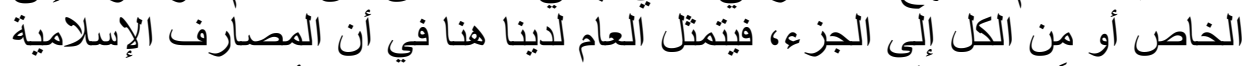

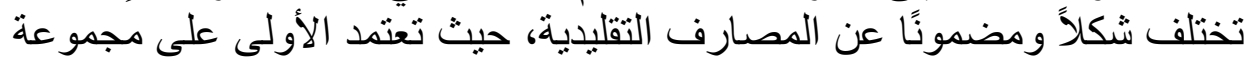
من المبادئ لا يمكن التنازل عن أي واحد منها، وإلا فقد المصندف الألى إسلاميته،

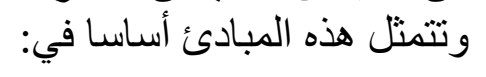

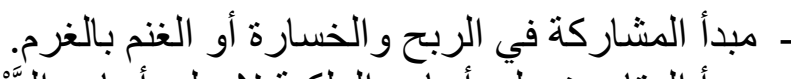

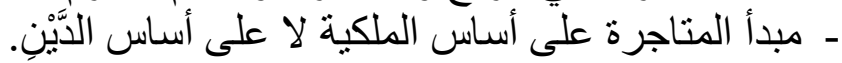

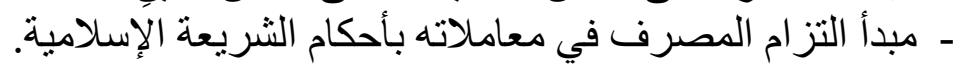

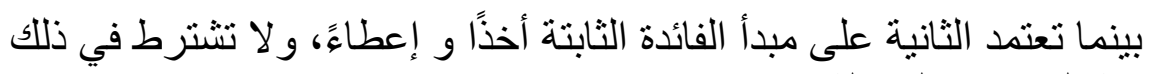
مشرو عية المشاريع المثولة.

و على هذا نجد أن العقود التي تقوم على مبلى مبدأ المشاركة في الربح و الخسارة

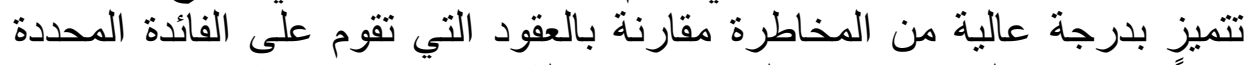

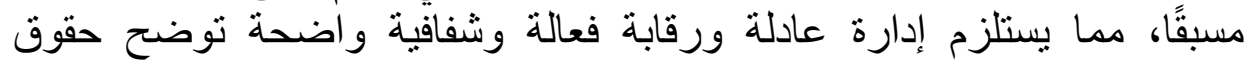

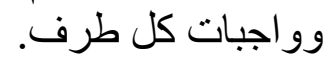

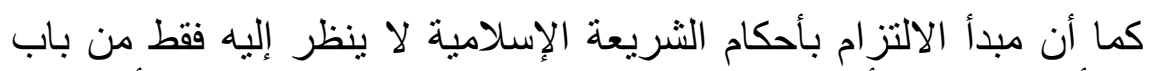

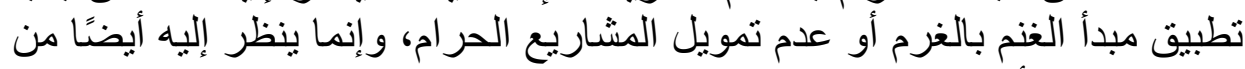

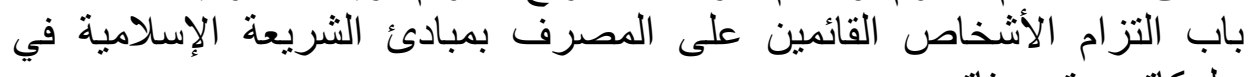

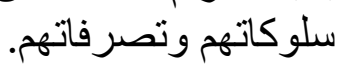

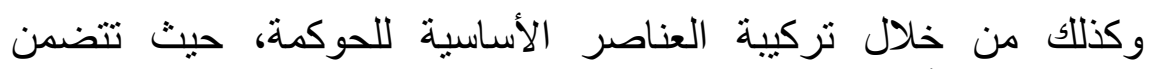

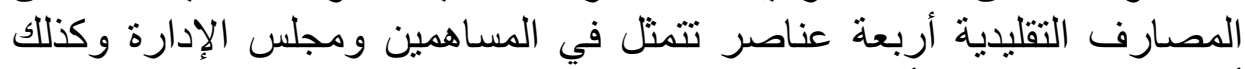
أصحاب المصالح الأخرى، بينما يزيد عنها في المصارف المين الإسلامية عنصر 


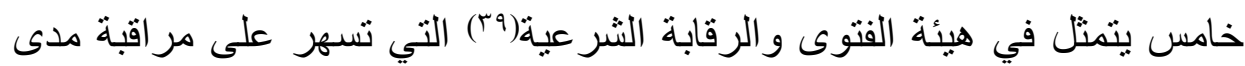

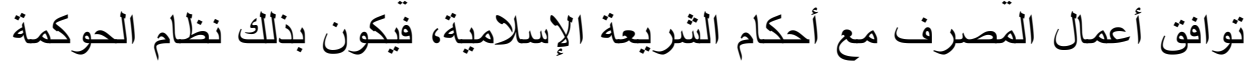

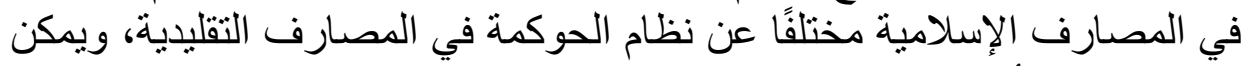

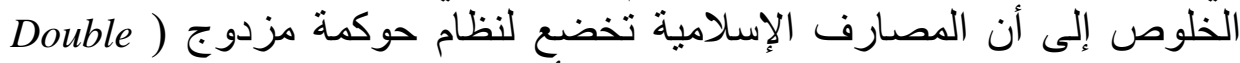
(Governance

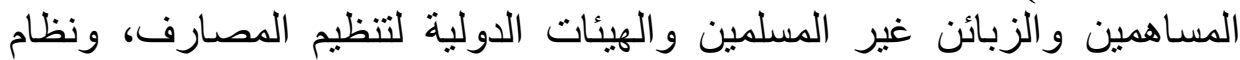

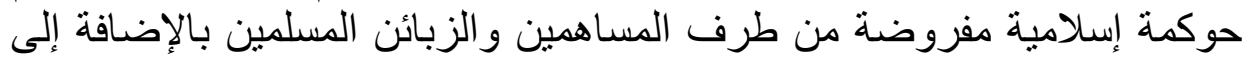

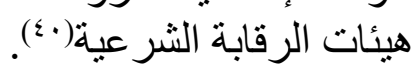
أي إن الحوكمة في المصارف الإسلامية تتميز بما يلي:

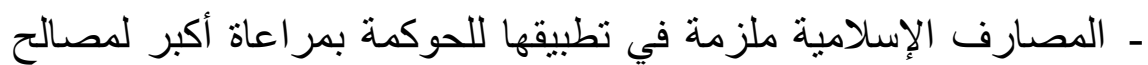

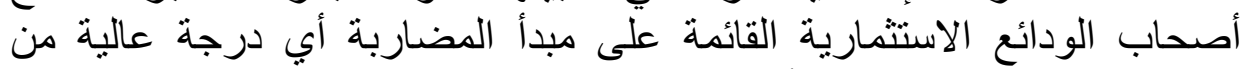

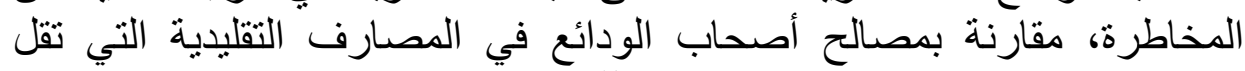

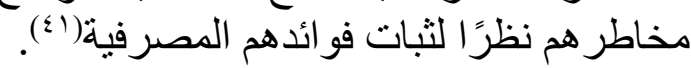

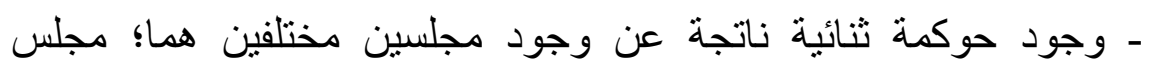

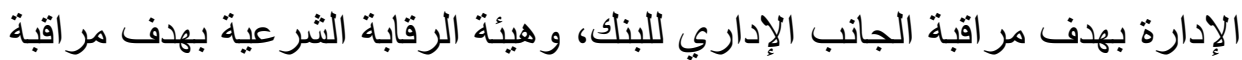
مدى تو افق العمليات المصرفية مع الثريعة الإسلامية.

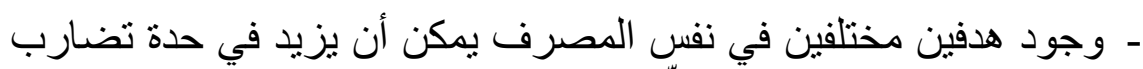

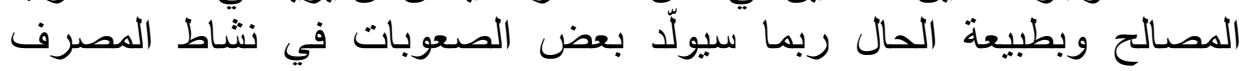
الإسلامي.

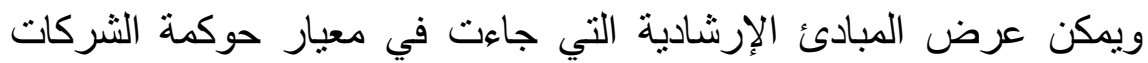
المالية الإسلامية الصادر عن مجلس الخدمات المالية الإسلامية بماليزيا في ديسمبر الثركار

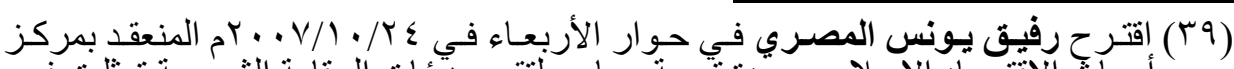

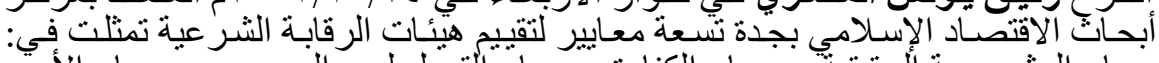

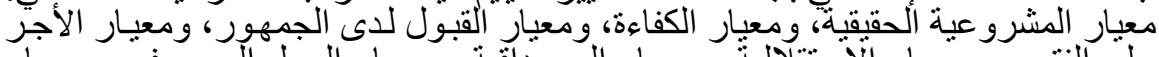

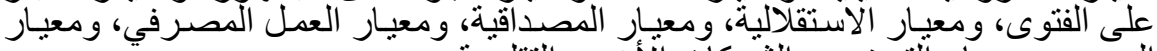

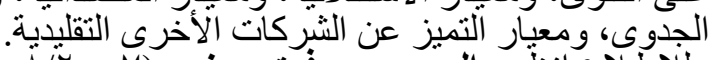

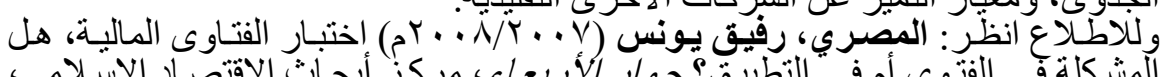

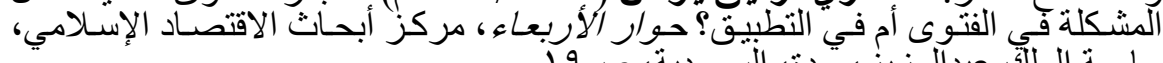

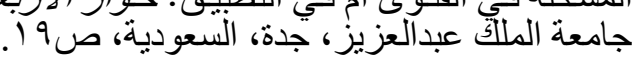

(40) Chapra, M.U. and Habib, A. (2002) Corporate Governance in Islamic Financial Institutions, occasional paper N:06, IRTI, Islamic Development Bank, p. 19.

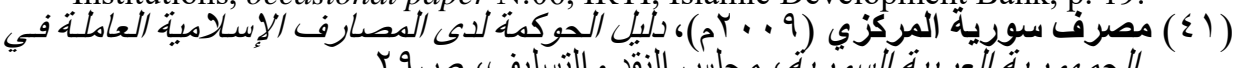

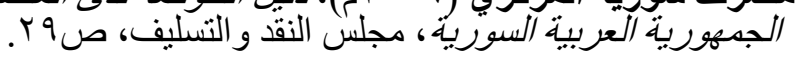


r ـ معيار حوكمة الثركات المالية الإسلامية الصادر عن مجلس الخدمات المالية الإسلامية

وقد تضمن المعيار سبعة مبادئ إرشادية على النحو التالي (r؟):

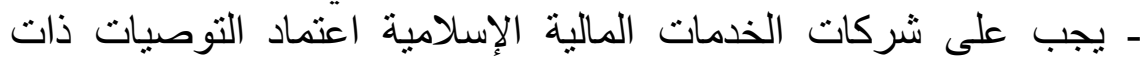

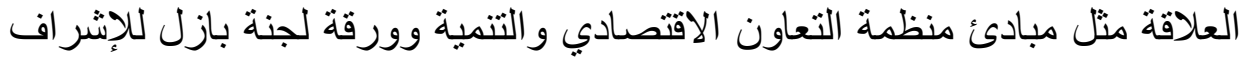

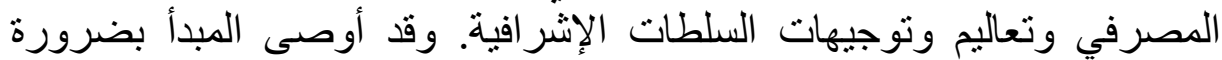
الالتز ام بأحكام الثشريعة الإسلامية و ومبادئها.

- تزويد مجلس الإدارة بالتقارير التي تبين مدى التزام شركة الخدمات

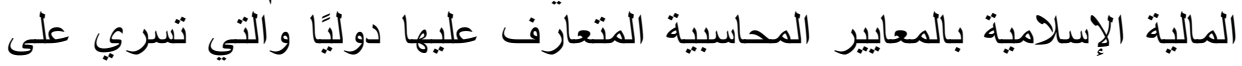
قطاع الخدمات المالية الإسلامية، وقد جاءت التهائة التوصية بضرورة قيام المصارف بإنشاء لجنة المر اجعة.

- يجب على شركات الخدمات المالية الإسلامية أن تتحمل مسؤولية ائتمانية

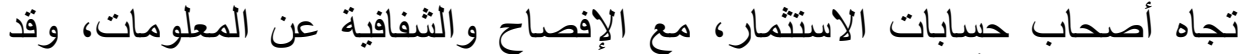

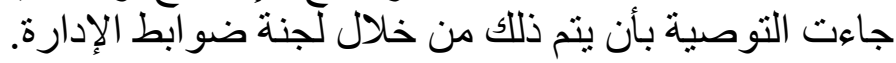

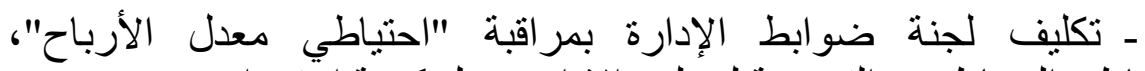
و "احتياطي المخاطر" والتوصية لمجلس الإدارة حول كيفية استخدامه.

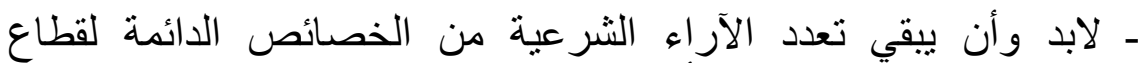

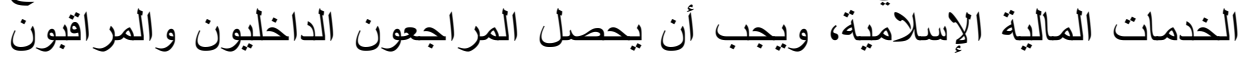

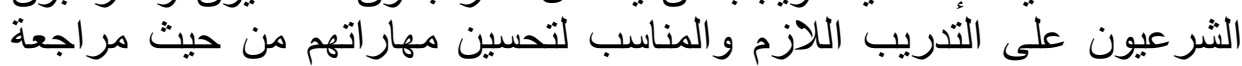

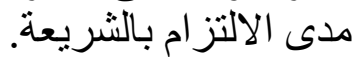
- يجب أن تعتمد شركة الخدمات المالية الإسلامية الثفافية في تطبيق أحكام

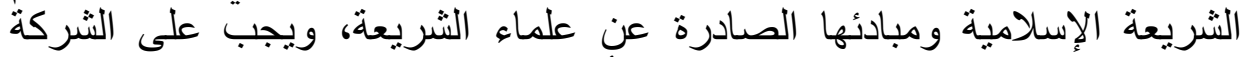

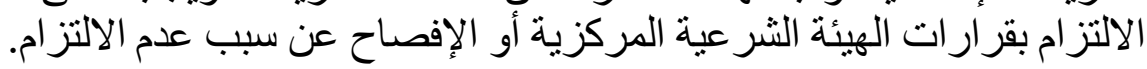

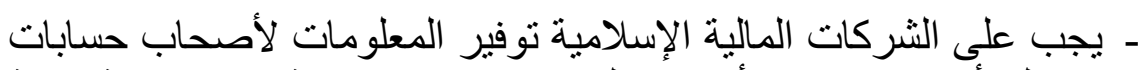
الاستثمار حول أسس توزيع الأرباح قبل فتح الإبة حساب الاستثمار وخاصة نسبة المشاركة في الأرباح و الخسائر.

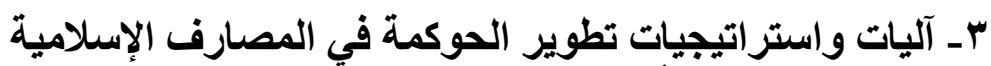

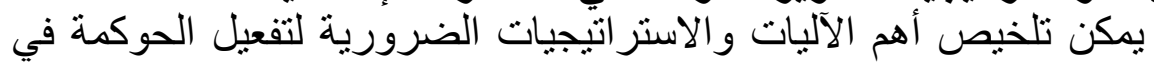
المصارف الإسلامية في النقاط التالية:

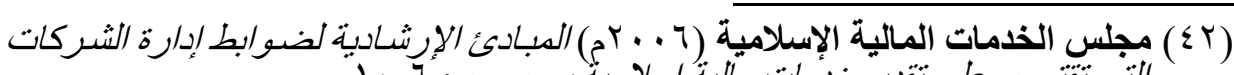

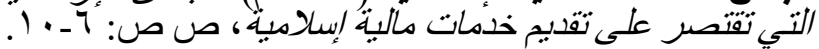


ـ العمل على تأسيس المزيد من شركات البنية التحتية الداعمة للمصارف

الإسلامية كإحدى الأدو ات الداعمة لمتطلبات الحوكمة.

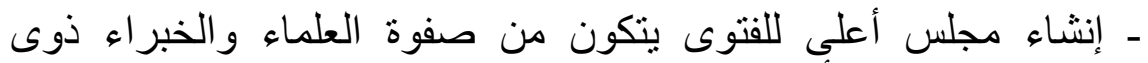

المعرفة الدقيقة والرصينة بأحكام الثرع وباء وبالمعاملات المصرفية، ليساهم في إثراء القر ار ات الثر عية.

- تفصيل العقود وتحديد شروطها وأحكامها بدقة من الناحيتين الثرعية

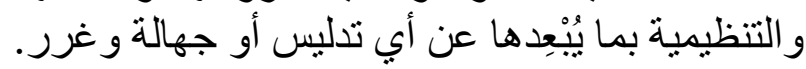

وبعدما عرفنا ما يميز حوكمة المصارف الإسلامية عن نظيرتها التقليدية

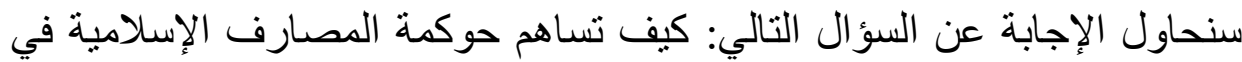

رفع كفاءتها؟

\section{؛ - دور الحوكمة في رفع كفاءة المصارف الإسلامية}

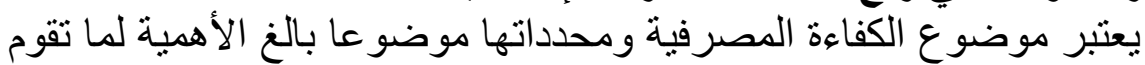

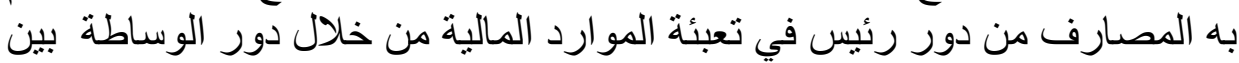

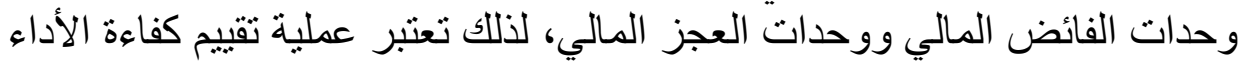

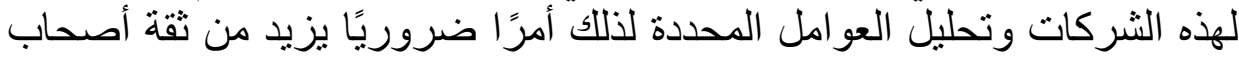

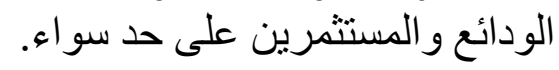

وتتمثل الكفاءة في العلاقة بين وسائل الإنتاج المستخدمة والنتائج المحققة،

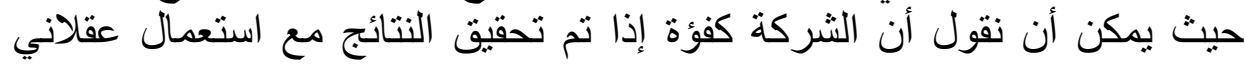

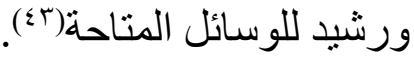

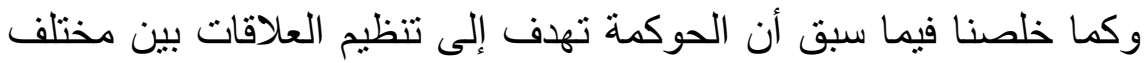

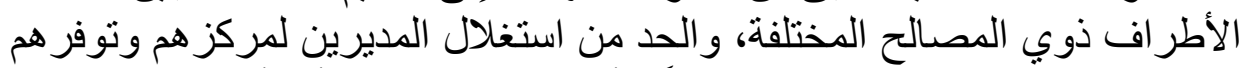

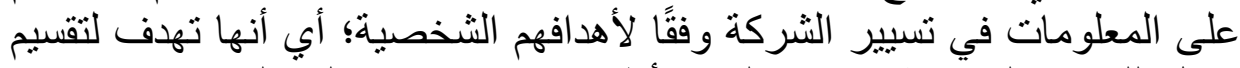

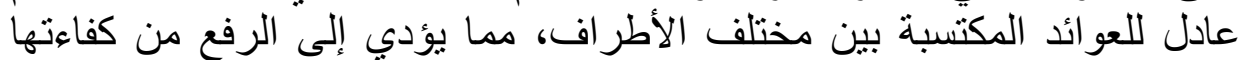

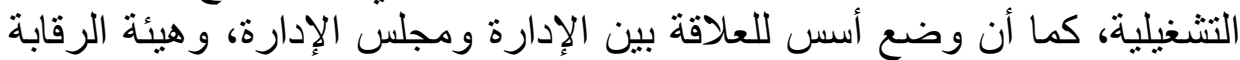

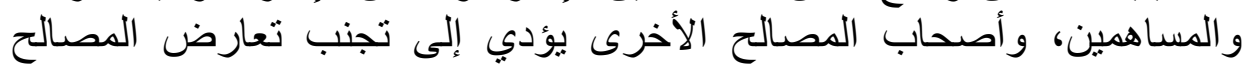

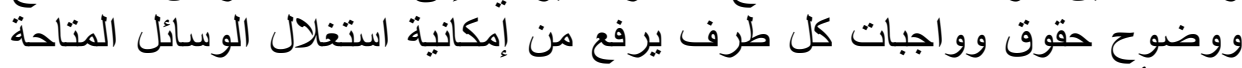

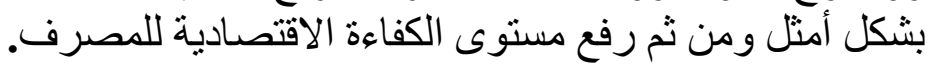

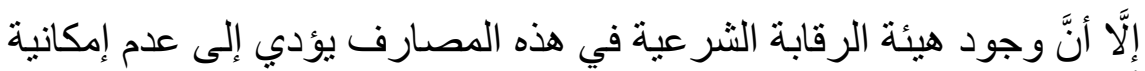

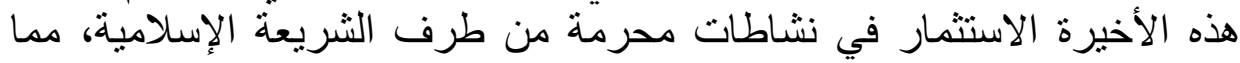

(43) MALO, J.L. and MATHE, J.C. (2000) L'essentiel du contrôle de gestion, Edition d'Organisation, 2ème édition, Paris, p.106. 


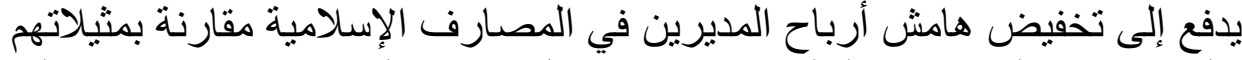

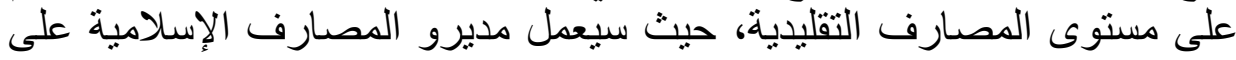
إلغاء كل العمليات المصرفية التي لا توافق الثريعة الإسلامية حتى ولو كانت بشكل كبير مربحة.

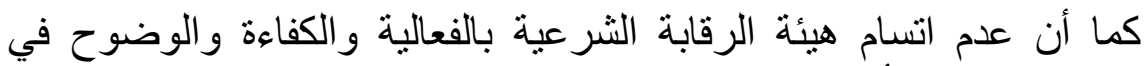

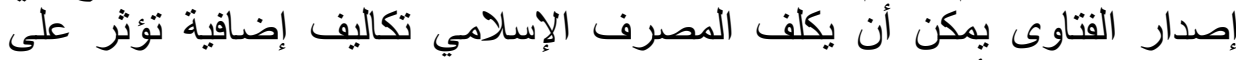

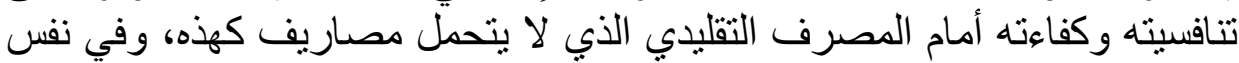

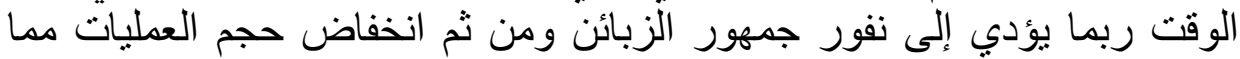

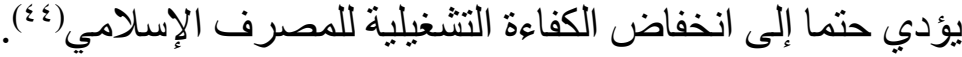

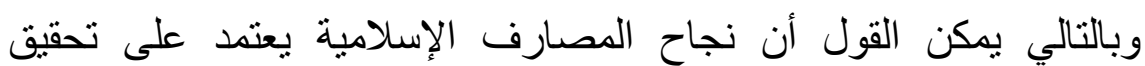

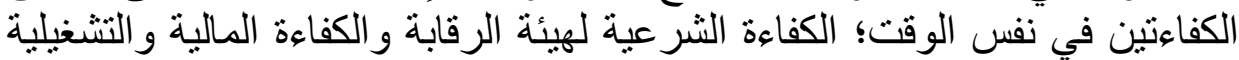

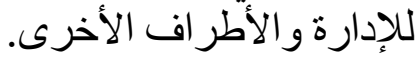

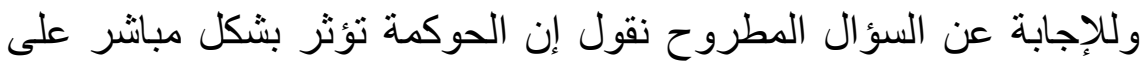

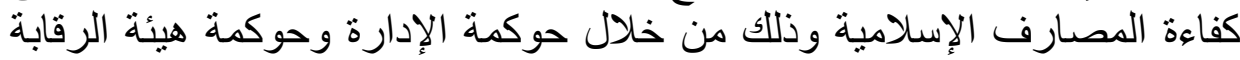

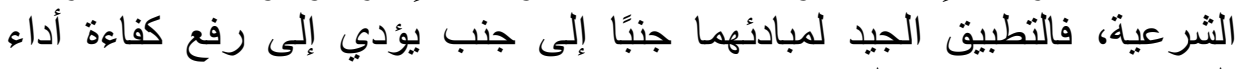

$$
\text { المصرف الإسلامي، و العكس صحيح. }
$$

\section{خامسا: دراسة تطبيقية على عيّتة من المصارف الإسلامية ا}

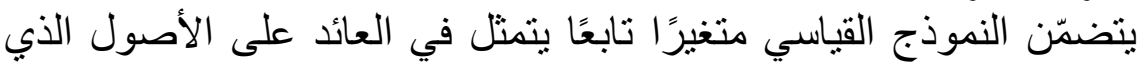

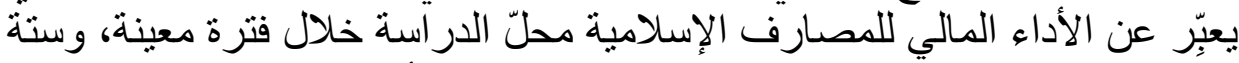

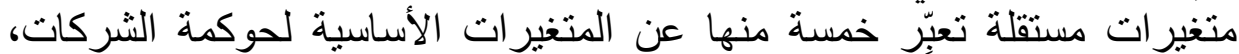

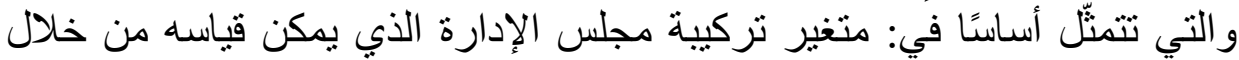

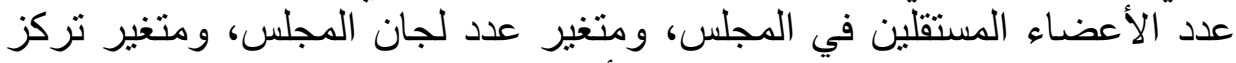

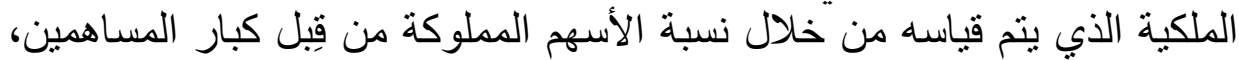

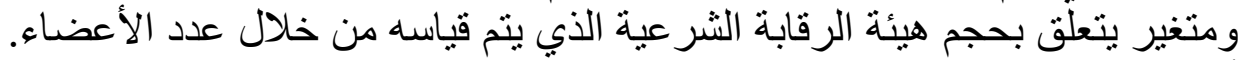

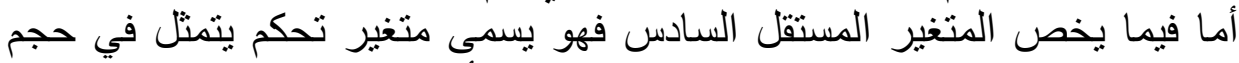

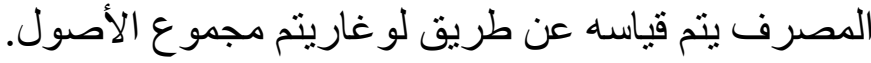
ويمكن توضيح ذلك كما يلي:

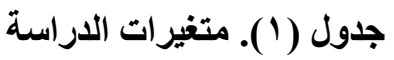

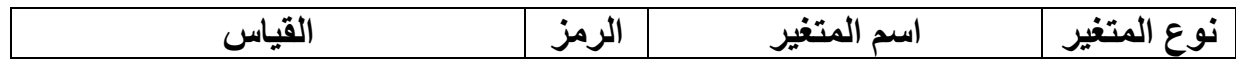

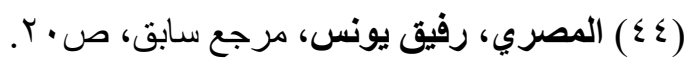




\begin{tabular}{|c|c|c|c|}
\hline 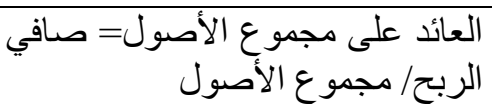 & ROA & الأداء & الت المتغير \\
\hline عدد الأعضاء المستقلين في المجلس & $\mathrm{BCM}$ & تركيبة مجلس الإدارة & \multirow{5}{*}{ المستقلة } \\
\hline عدد اللجان في مجلس الإدارة & $\mathrm{CBD}$ & لجان المجلس & \\
\hline نسبة الأسهم المملوكة من قِبل كبار & $\mathrm{OCN}$ & تزكز الملكية & \\
\hline عدد أعضـاء هيئة الرقابة الشر عية & SSB & حجم هيئة الرقابة الثرعية & \\
\hline لو غاريتم مجموع الأصول & SZE & حجم المصرف (متضير التحكم) & \\
\hline
\end{tabular}

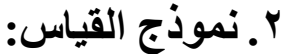

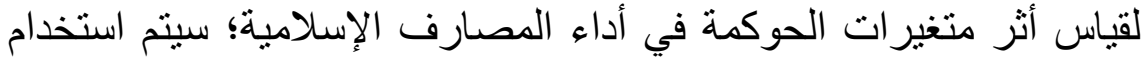

طريقة تحليل الارتباط وفقًا للمعادلة التالية:

$\mathrm{ROA}_{\mathrm{it}}=\alpha_{0}+\beta_{1} \mathrm{BCM}_{\mathrm{it}}+\beta_{2} \mathrm{BSZ}_{\mathrm{it}}+\beta_{3} \mathrm{CBD}_{\mathrm{it}}+\beta_{4} \mathrm{OCN}_{\mathrm{it}}+\beta_{5} \mathrm{SSB}_{\mathrm{it}}+\beta_{5} \mathrm{SZE}_{\mathrm{it}}+\varepsilon_{\mathrm{it}}$

(ROA $)$

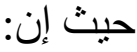
(BCM $)$ :BCMit

CBDit :OCNit

SSBit

:SZEit عit (الخطأ العشو ائي.

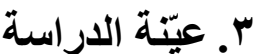

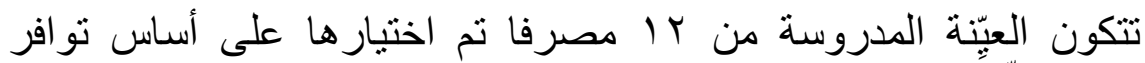

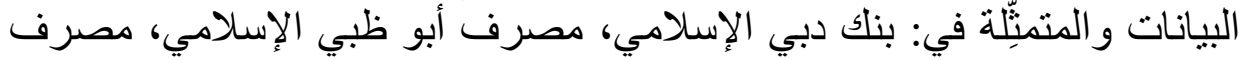

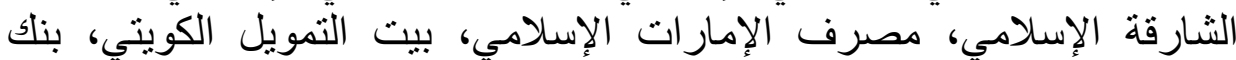

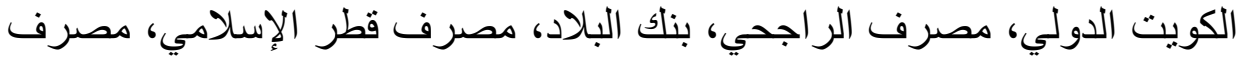

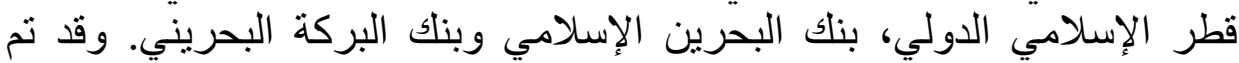

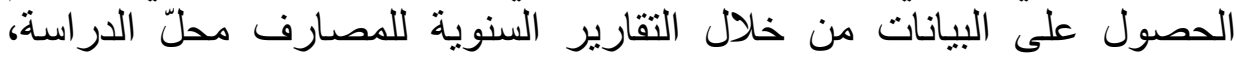

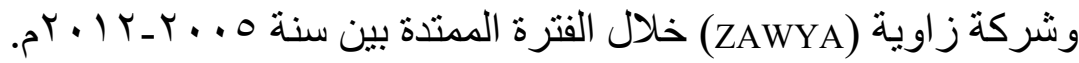
ويمكن تلخيص تطور متوسط متغير ات المصارف الإسلامية محلّ الدر اسة الته

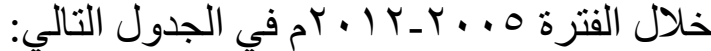

\begin{tabular}{l|l|l|l|l|l|} 
SZE & SSB & OCN & CBD & BCM & ROA \\
\hline
\end{tabular}


أثر تطبيق قو اعد حوكمـة الشركات في أداء المصـارف الإسلاميـة: دراسة حالة دول منطقة الخليج

$1 \leqslant \mu$

\begin{tabular}{|c|c|c|c|c|c|c|}
\hline$\varepsilon, 0 r$ & 2.5 &., $1 V$ & $r$ & $r$ & ., $\varepsilon$ & م... \\
\hline $0, \varepsilon$ & 3.5 &., 19 & $r$ & $\Gamma$ &., 0 & F. T \\
\hline$T, \cdot Y$ & 3.5 & $\cdot, Y_{1}$ & $\mu$ & $\Gamma$ & $\cdot, 7$ & R...V \\
\hline $7, Y \leqslant$ & 4 & $\cdot$, ro & $\mu$ & $\mu$ & $\cdot, \varepsilon$ & A. I \\
\hline $0,1 Y$ & 4.5 & $\cdot, r \wedge$ & $\varepsilon$ & $\varepsilon$ & $\cdot, \Lambda$ & p. q \\
\hline $7,7 \varepsilon$ & 5 & $\cdot, \mu$ & $\varepsilon$ & 7 & $\cdot, 7$ & $a^{r} \cdot 1$. \\
\hline$V, Y \wedge$ & 5.5 & • & 0 & $\Lambda$ & $\cdot, V$ & $a^{r+11}$ \\
\hline 1,09 & 5.5 & • & 0 & $\Lambda$ & $\cdot, 7$ & $r^{r} \cdot 1 r$ \\
\hline
\end{tabular}

إعداد الباحثان استنادا إلى التقارير السنوية للمصارف محل الدراسة

ويمكن توضيح ذلك أكثر من خلال الثكل التالي:

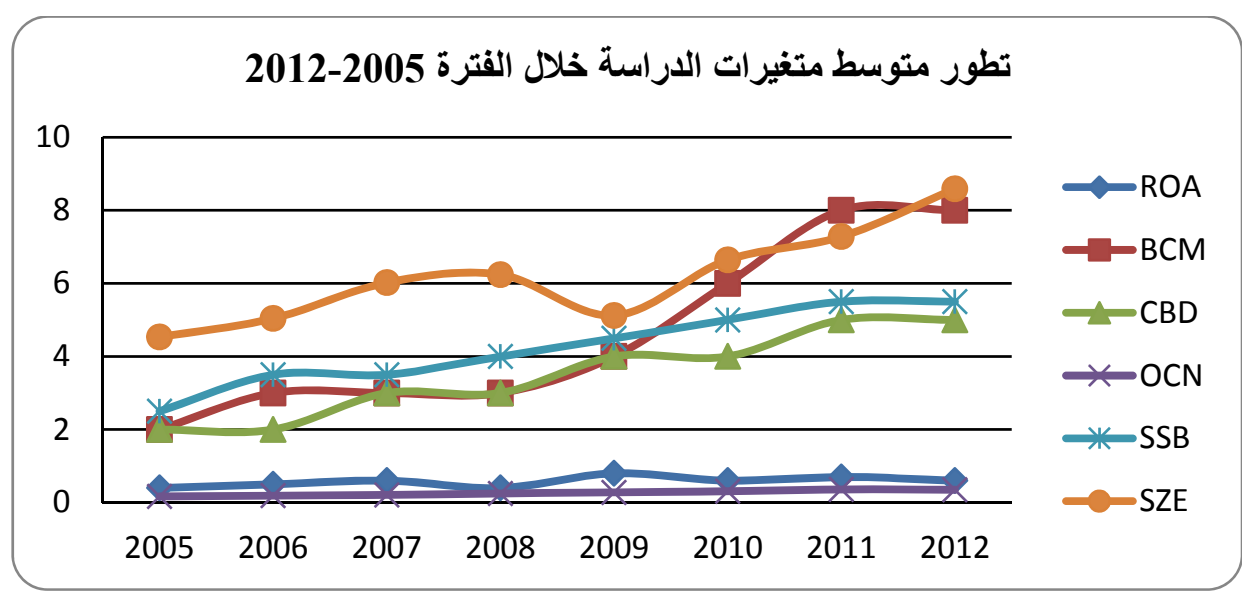

إعداد الباحثنان استتادًا إلى البيانات الموجودة في الجدول رقم (Y)، وباستخدام برنامج الإكسل (Excel)

\section{؛ ـ البيانات الإحصائية}

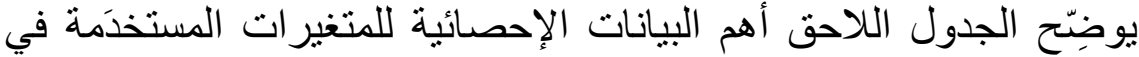

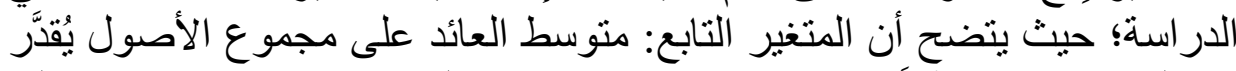

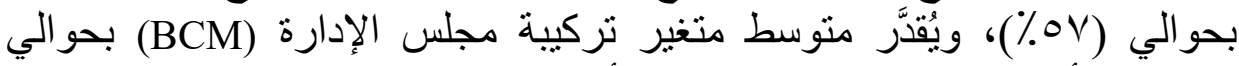

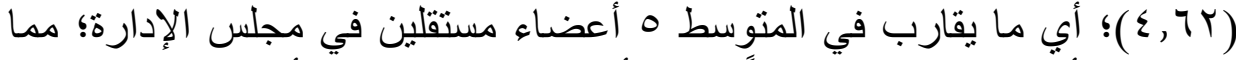

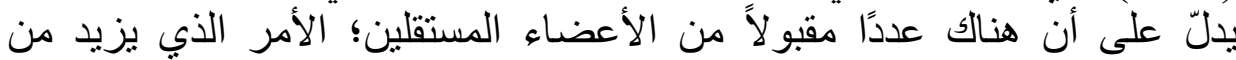
استقلالية وشفافية المجلس؛ ومن ثمّ فعالية حوكمة الثركات. 


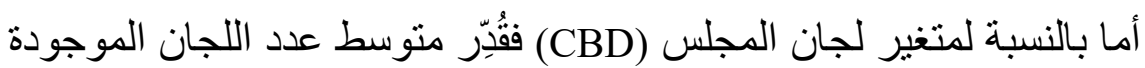

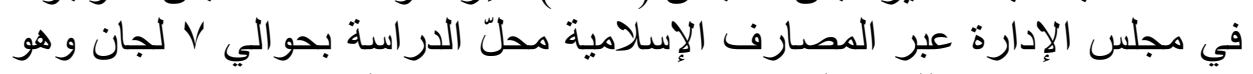
يقارب متوسط عدد اللجان التي توصي بها قو اعد حوكمة الثركات.

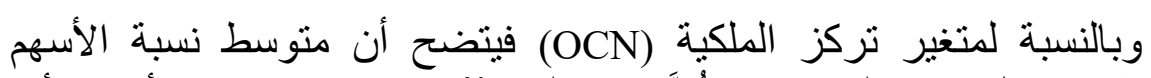

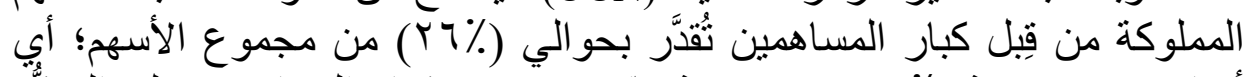

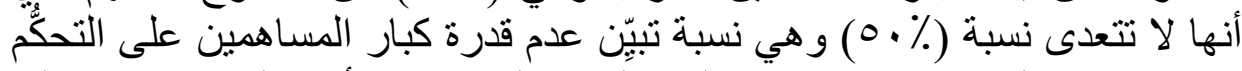

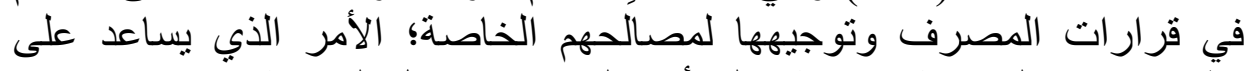

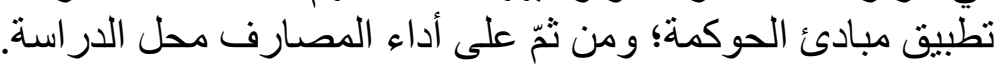

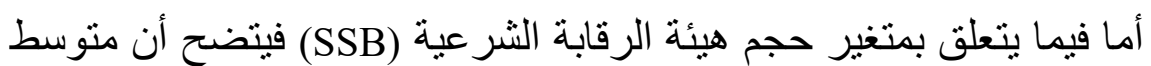

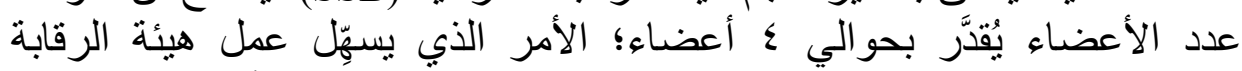

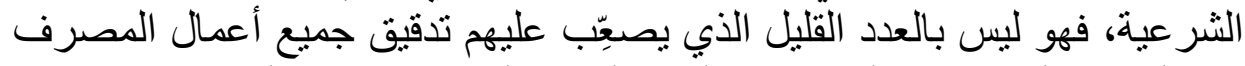

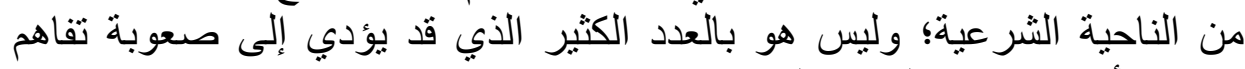
وتناسق أعضاء هيئة الرقابة الثر عية. 
أثر تطبيق قو اعد حوكمـة الثركات في أداء المصـارف الإسلاميـة: در اسة حالة دول منطقة الخليج

$1 \leqslant 0$

جدول (r). البيانات الإحصائية لمتغيرات الدراسة

\begin{tabular}{|c|c|c|c|c|}
\hline الانحر اف المعياري & المتوسط & أعظد قيمة & أدنح قيمة & المتغير \\
\hline 1.069 & 0.57 & 0.80 & 0.40 & ROA \\
\hline 2.386 & 4.62 & 8.00 & 2.00 & BCM \\
\hline 2.295 & 7.12 & 10.00 & 4.00 & CBD \\
\hline 0.072 & 0.26 & 0.36 & 0.17 & OCN \\
\hline 0.123 & 4.25 & 5.5 & 2.5 & SSB \\
\hline 1.331 & 6.18 & 8.59 & 4.53 & SZE \\
\hline
\end{tabular}

إعداد الباحثنان باستخدام برنامج (Eviews)

๑ـ الار اسة القياسبة

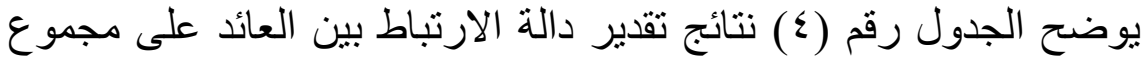

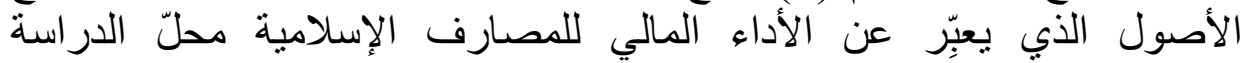

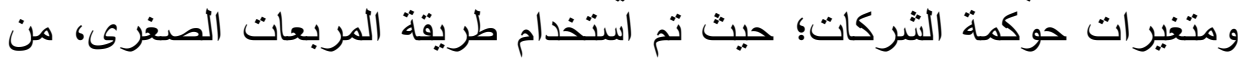

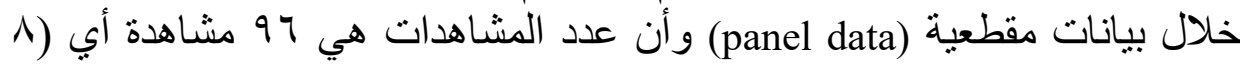

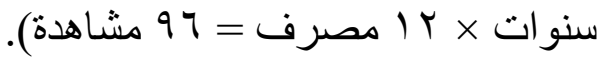

جدول (؛). تقدير معاملات الدالة

Dependent Variable: ROA

Method: Least Squares

Sample: 20052012

Included observations: 96

\begin{tabular}{|l|l|l|l|l|}
\hline Variable & Coefficient & Std. Error & t-Statistic & Prob. \\
\hline C & 0.763537 & 0.066693 & 11.44848 & 0.0075 \\
\hline BCM & 0.025301 & 0.010760 & 2.351519 & 0.0430 \\
\hline CBD & 0.348128 & 0.029398 & 11.84187 & 0.0071 \\
\hline OCN & -7.614178 & 0.853048 & -8.925854 & 0.0123 \\
\hline SSB & 0.279575 & 0.036588 & 7.641151 & 0.0167 \\
\hline SZE & -0.112323 & 0.011096 & -10.12278 & 0.0096 \\
\hline R-squared & 0.994828 & Mean dependent var & 0.575000 \\
\hline Adjusted R-squared & 0.981897 & S.D. dependent var & 0.138873 \\
\hline S.E. of regression & 0.018685 & Akaike info criterion & -5.008501 \\
\hline Sum squared resid & 0.000698 & Schwarz criterion & -4.948920 \\
\hline Log likelihood & 26.03400 & F-statistic & 76.93642 \\
\hline Durbin-Watson stat & 2.238717 & \multicolumn{2}{|l|}{ Prob(F-statistic) } & 0.012880 \\
\hline
\end{tabular}

(Eviews) (عداد الباحثنان باستخدام برنامج)

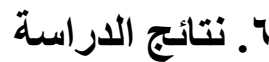

يوضح الجدول السابق المعاملات المقدَّرة للنموذج وقيمة (t) الإحصائية،

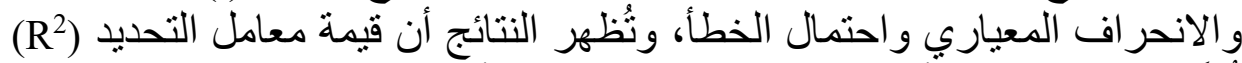

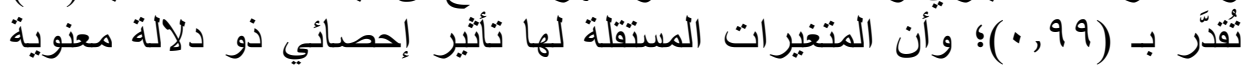


عند مستوى معنوية (\%) (Significant)

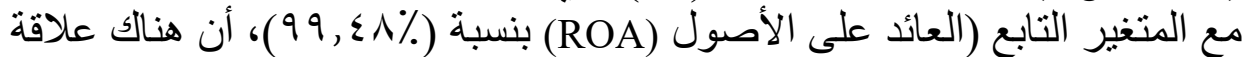
قوية جدًا بين العائد على الأصول (ROA) ومتغير الأن حوكمة الثركات.

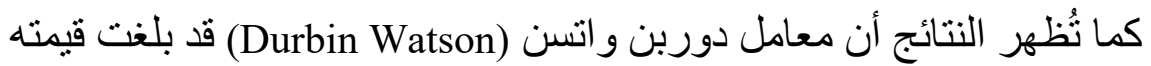

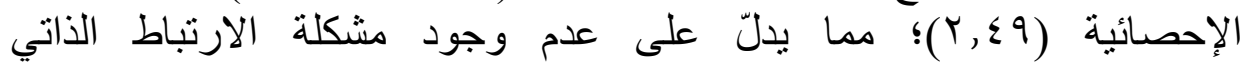
بين المتغير ات المستقلة. (Autocorrelation)

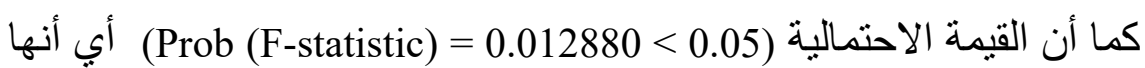

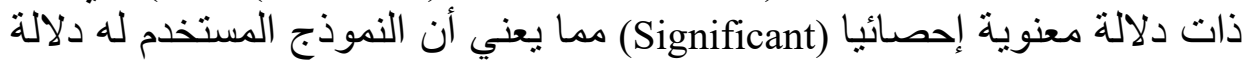

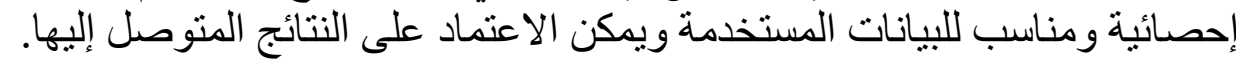

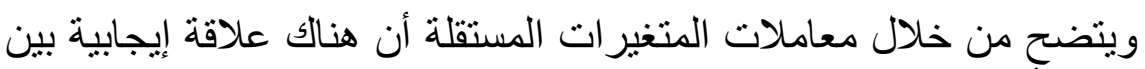

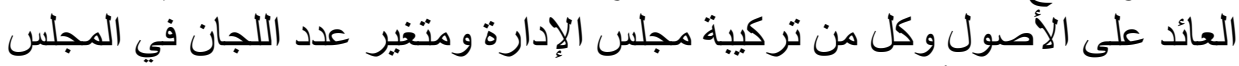

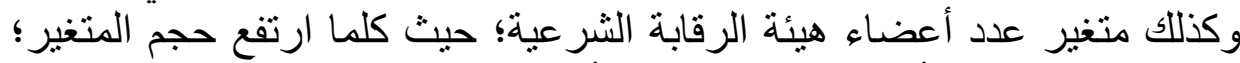

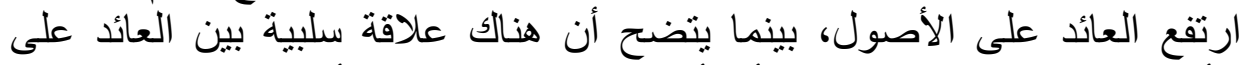

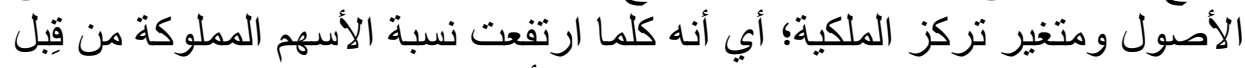

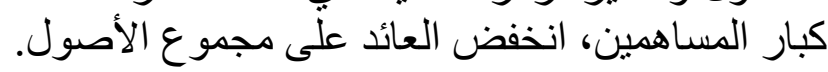




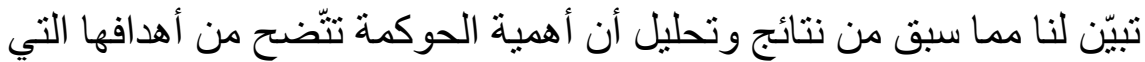

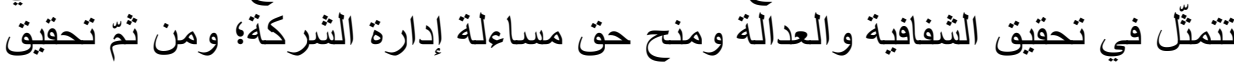

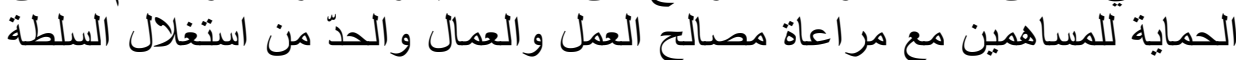
في غير المصلحة العامة؛ بما يؤدي إلى تنمية الاستثمار ات، والم المدخر ات ات وتعظيم

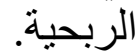

إن وجود نظام فعّال وقادر على توفير الثقة ومكافحة الفساد في الثركات

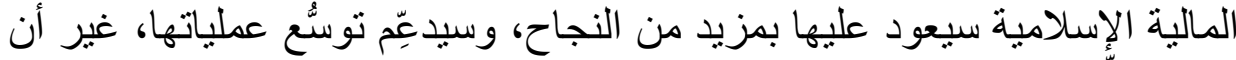

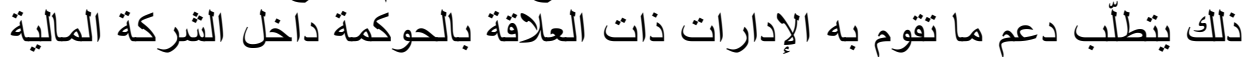
كادارة الالتز ام و المر اجعة الداخلية و القانونية وكذا إدارة الرقابة الثابة الثرعية بنو عيها الداخلية و الخارجية.

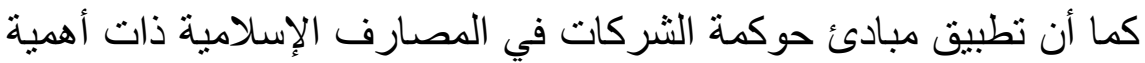

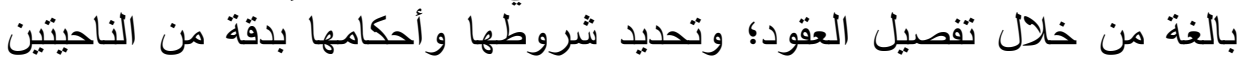

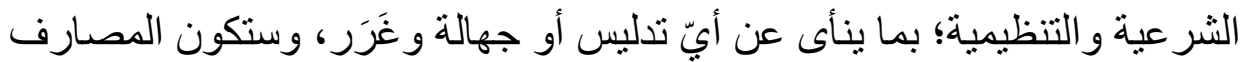

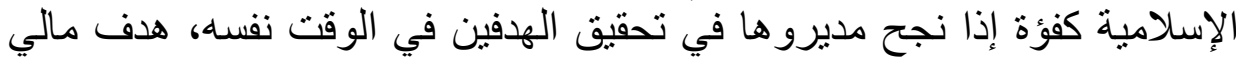

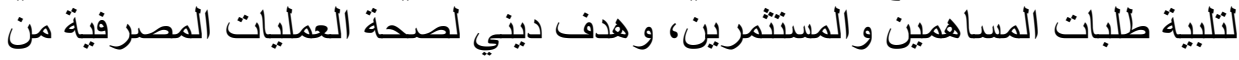

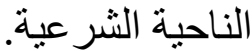

توصئلت الدر اسة التطبيقية إلى النتائج التالية:

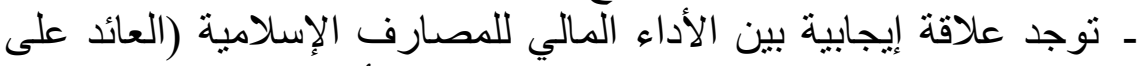
الأصول) ومتغير الحوكمة: تركيبة مجلس الإدارة (عدد الأعضاء المستقلين).

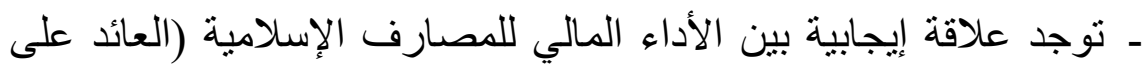
الأصول) ومتغير الحوكمة: عدد اللجان في مجلس الإدارة الإنة الإداء

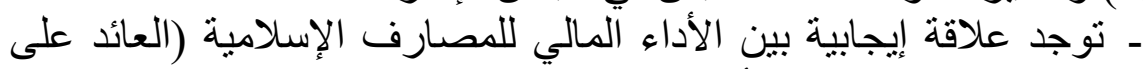
الأصول) ومتغير الحوكمة: عدد أعضاء هيئة الر قابة الثر عية. - توجد علاقة سلبية بين الأداء المالي للمصارف الإسلامية (العائد على الإئ الأصول) ومتغير الحوكمة: تركز الملكية (نسبة الأسهم المملوكة من قِبل كبار

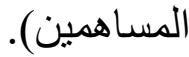

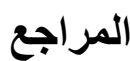

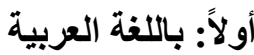
الخضيري، محسن أحمد (•99 (م) الإدارة في الإسلام، وقائع ندوة رقم الب، معهد البحوث و التدريب، البنك الإسلامي للتنمية، جدة، السعودية. 


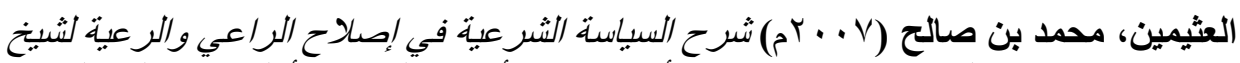
الإسلام تقي الدين بن تيبية، تحقيق أبو عمرو الأثري، الطبعة الأولى، دار الثراعي الغد الجديد،

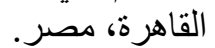

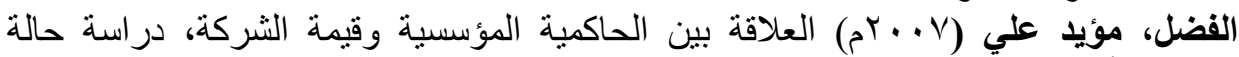

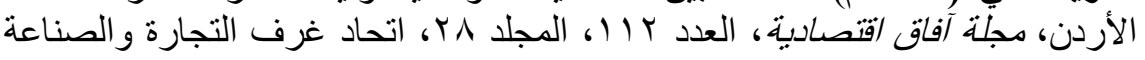

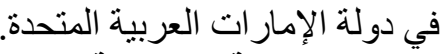

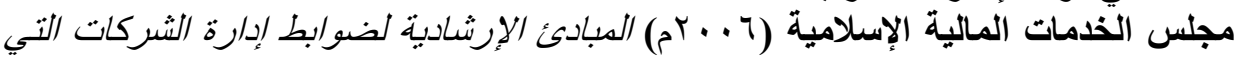
تقتصر على تقليم خدمات مالية إسلامية.

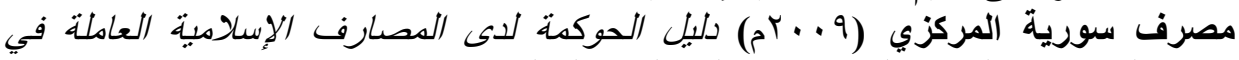

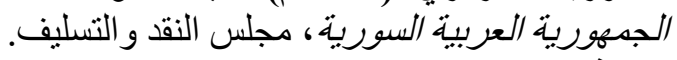

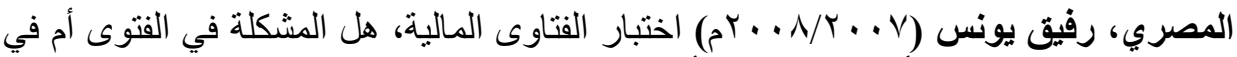

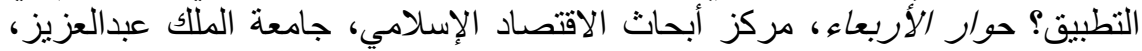

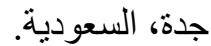
المعهر المصرفي المصري (د.ت.) مفاهيم مالية، نظام حوكمة المصارف، العدد السادس،

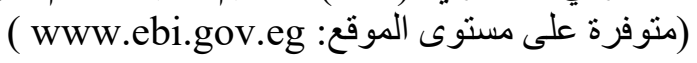




$$
\text { ثانيًَا: باللغة الثر أطبيق قو اعد حوكمـة الثركات في أداء المصسارف الإسلاميـة: دراسة حالة دول منطقة الخليج }
$$

Bancel, F. (1997) la gouvernance des entreprises, Economica, Paris.

Bessire, D. and Meunier, J. (2001) Conception du gouvernement des entreprises et modèles d'entreprise: une lecture épistémologique, Finance d'entreprise, CREFIB, Economica, Paris.

Encyclopédie de wikipedia sur site :http://fr.wikipedia.org/w/index.php?oldid=45800587.

Charreaux, G. (2002) À la recherche de nouvelles fondations pour la finance et la gouvernance d'entreprise, Finance Contrôle Stratégie, Vol. 5, No. 3.

Louizi, G. (2006) L'impact du conseil d'administration sur la performance des banques tunisiennes, XVème Conférence Internationale de Management Stratégique, Annecy / Genève 13-16 Juin.

Hirogoyen, G. and Caby, J. (2001) La création de valeur de l'entreprise, Economica, paris.

Jean-Pierre, P. (2000) La stabilité financière nouvelle urgence pour les banques centrales, bulletin de la banque de France, No. 84.

MALO, J-L. and MATHE, J-C. (2000) L'essentiel du contrôle de gestion, Edition d'Organisation, 2ème édition, Paris.

Nguena O.J. el al. (2001) Introduction au management de la valeur, Dunod, Paris.

Plusieurs auteurs. (1998) L'art de la finance, Glossaire Financial Times Limited, Village Mondial ; Paris.

Thierry, W.G and el al. (2003) Développement durable et gouvernement d'entreprise: un dialogue prometteur, édition d'organisation, Paris,.

Zied, C. and Pluchart, J.J. (2006) la gouvernance de la banque islamique, proposition de communication.

$$
\text { ثالثًا: باللغة الإنجليزية }
$$

Cadbury Committee (1992) Report of the Committee on the Financial Aspects of Corporate Governance, London, Gee and Co Ltd.

Chapra, M.U. and Habib, A. (2002) Corporate governance in Islamic financial institutions. Occasional paper No. 6. Islamic Research and Training Institute (IRTI), Islamic Development Bank.

Fawzi, S. (2003) Assessment of corporate governance in Egypt. Working paper No. 82, the Egyptian Center of Economic Studies, Egypt, pp 1-45.

Matoussi, H. and Grassa, R. (2012) "Is Corporate Governance Different For Islamic Banks? A Comparative Analysis Between The GCC Context and The SEA Context“" Working Paper No.734, Economic Research Forum, Egypt.

Mehram, H. (2004) Corporate governance in the banking and financial services industries. Journal of Financial Intermediation, vol. 13, issue 1, pp. 1-5.

Organization Economic Cooperative Development (2000) Principles of Corporate Governance, OECD Publications Service.

Ramiz, U.R. and Mangla, I. (2010) Corporate Governance and Performance of Financial Institutions in Pakistan: A Comparison between Conventional and Islamic Banks in Pakistan, The Pakistan Development Review, Pakistan.

Sebastian, M. (2007) International and Mena wide trends and developments in bank and corporate governance, the institute of banking. Proceedings from IFC: Corporate Governance for Banks in Saudi Arabia Forum. May 22-23, Riyadh. 


\title{
The Impact of the Application of Corporate Governance Rules on the Performance of Islamic Banks: Evidence from the GCC Region
}

\author{
Chaouki Bourakba and Abdelhalim Gherbi \\ Assistant professor, Associate professor \\ Faculty of Economics and Administrative Sciences \\ Al-Imam Muhammad Ibn Saud Islamic University \\ Riyadh, Saudi Arabia.
}

\begin{abstract}
Through this paper we seek to determine the relationship between the variables of corporate governance and financial performance of Islamic banks. Due to the special nature of the banking industry; which affects financial stability of the entire economy, we discussed theoretically the concept of corporate governance in the banking sector in general and Islamic banking in particular. Much of the discussion has been devoted in highlighting the specificity of governance in Islamic banks. These banks are subject to 'Double Governance'; Anglo-Saxon governance system and Islamic Governance System. We, then, measured the impact of corporate governance variables on financial performance through an empirical study on a sample of Islamic banks during the period 2005-2012 in the GCC region.

The study found that there is a very strong relationship between the variables of governance and financial performance of Islamic banks; where there is a positive relationship between return on assets and the composition of the Board of Directors, the size of the Board of Directors, the number of committees in the Council, as well as the number of members of the Shariah Supervisory Board. At the same time it has been found that there is a negative relationship between return on assets and owner concentration variable.
\end{abstract}

Keywords: Corporate governance, Islamic banks, GCC Region, Financial performance 


\section{د. شوقي عاشور بورقبة}

أستاذ الأعمال المصرفية المساعد بكلية الاقتصاد والعلوم الإدارية، جامعاة

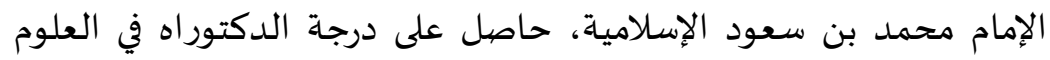

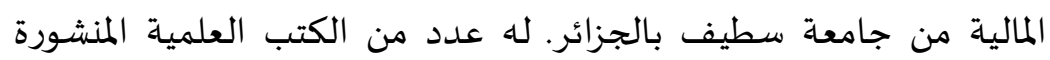

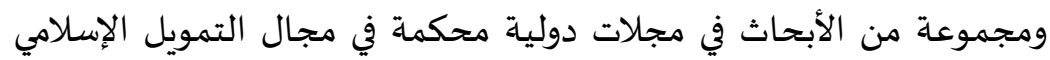
والأعمال المصرفية، وهو أيضا محكم لعدة مجلات دولية، كما حضر وشارك

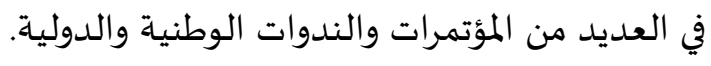
البريد الإلكتروني: chawki62000@yahoo.fr

\section{د. دبدالحليم عمار غربي}

أستاذ الأعمال المصرفية المشارك بكلية الاقتصاد والعلوم الإدارية، جامعة الإمام محمد بن سعود الإسلامية. حاصل على درجة الدكتوراه في العلوم المالية والمصرفية. إنتاجه العلمي: لله عدد من الكتب المنشورة إلكترونياً، ومجموعاة من الأبحاث

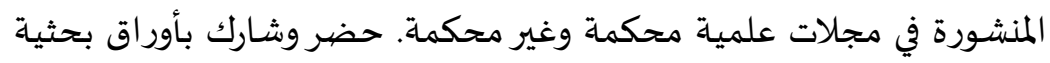

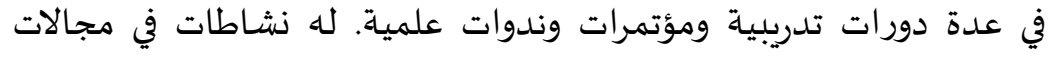

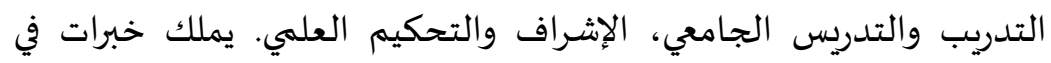

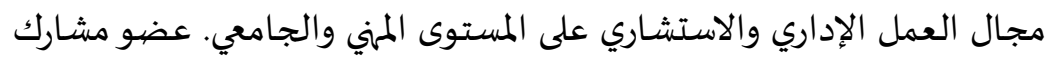

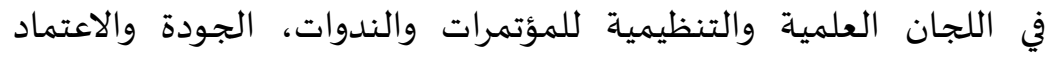

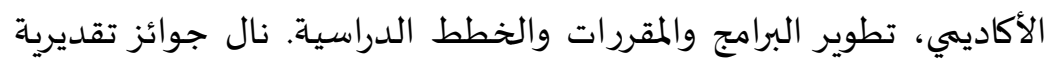

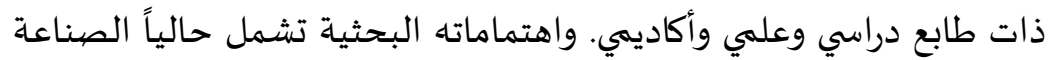

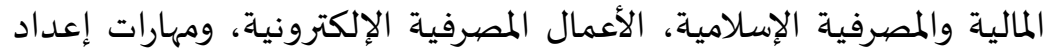
البحوث العلمية. البريد الإلكتروني: halimgherbi@yahoo.fr 